\title{
Supporting Medical Ward Rounds Through Mobile Task and Process Management
}

\author{
Rüdiger Pryss, Nicolas Mundbrod, David Langer, and Manfred Reichert \\ Institute of Databases and Information Systems, Ulm University, Germany \\ \{ruediger.pryss, nicolas.mundbrod, david.langer, manfred.reichert\}@uni-ulm.de
}

\begin{abstract}
In a hospital, ward rounds are crucial for task coordination and decision-making. In the course of knowledge-intensive patient treatment processes, it should be possible to quickly define tasks and to assign them to clinicians in a flexible manner. In current practice, however, task management is not properly supported. During a ward round, emerging tasks are jotted down using pen and paper and their processing is prone to errors. In particular, staff members must manually keep track of the status of their tasks. To relieve them from such a manual task management, we introduce the MEDo approach. It transforms the pen and paper worksheet to a digital user interface on a mobile device. Thereby, MEDo integrates process support, task management, and access to the patient record. Interviews of medical staff members have revealed that they crave for a mobile process and task support. This has been further confirmed in a case study we conducted in four different wards. Finally, in user experiments, we have demonstrated that MEDo puts task acquisition on a level comparable to that of pen and paper. Overall, MEDo enables users to create, monitor and share medical tasks based on a mobile and user-friendly platform.
\end{abstract}

Key words: knowledge-intensive process, healthcare process, mobile task management

\section{Introduction}

The increasing number of options to streamline production and administrative services based on advanced information technologies have given rise to a structural shift of value-adding jobs. Standardized tasks are more and more supported by IT or outsourced to cut operative costs $[1,2]$. Along this trend, the support of knowledge-intensive processes has gained more attention as well [3]. Respective processes are considered as the strong opposite to production processes. In particular, knowledge-intensive processes face unplanned and complex situations. Further, they strongly depend on expertise and skills of the stakeholders involved. Generally, knowledge-intensive processes can be characterized as follows [4]:

- Uncertainty: Knowledge-intensive processes face complex and unplanned situations. An unmanageable set of influencing factors, intertwined via dynamic 
correlations, makes it impossible for involved stakeholders to foresee the process in all details before starting its execution.

- Goal Orientation: Struggling with uncertainty, a common goal is used as the solid basis for all stakeholders in knowledge-intensive processes. Therefore, all activities and resources are aligned to achieve the defined goal. To ease the achievement of a goal, sub-goals may be defined.

- Emergence: A knowledge-intensive process usually comprises mutual phases of planning and working. Having performed a number of activities, involved stakeholders usually evaluate work results first in order to properly focus on the planning of activities to be performed in the following. Such an agile planning and working let knowledge-intensive processes gradually emerge towards the defined goal.

- Growing Knowledge Base: Participants of a knowledge-intensive processes leverage their expertise and experiences to effectively achieve a common goal. Hence, they expand their knowledge base during process execution. Further, they create explicit knowledge through intermediate and final work results.

These characteristics expose core challenges with respect to the support of knowledge-intensive processes. In particular, the latter require a high degree of flexibility and agility not provided by contemporary process-aware information systems.

\subsection{Problem Statement}

In previous work, we analyzed various processes from the healthcare domain [5]. We characterized them as knowledge-intensive as they are driven by many factors and expose complex interdependencies, and recurring context switches. Particularly challenging are the processes taking place in the context of clinical ward rounds.

For ward rounds in a hospital, there is a high demand for improving the interaction and communication among healthcare professionals [6]. Medical problems of inpatients are becoming increasingly complex and patient data needs to be managed at the bedside. Although information technology, which is tailored to ward round demands, has reached a mature level, there is a lack of process-aware task support during ward rounds [7]. However, this is not surprising considering the fact that ward rounds constitute knowledge-intensive processes. In turn, this type of process is not properly supported by existing process management technology as its steps and resources cannot be completely foreseen. Instead, processes are driven based on the expertise and experiences at run time.

In order to understand how an adequate support for knowledge-intensive processes could be smoothly integrated into medical practice, we attended a multitude of ward rounds, interviewed medical staff, and analyzed existing solutions in a case study. In turn, these activities revealed two major issues: First, the current paper-based task worksheet needs to be transferred to a digital, mobile 
variant. Note that clinicians use worksheets as their personal "information system" to organize daily tasks. In current practice, however, data gathered with paper sheets is not consistently linked to the one managed by the hospital information system in use. When adding a task to her sheet during a ward round, for example, a physician makes notes like "Mrs.Richards: X-ray request arranged, monitor status and check images today". In the pen and paper version, basically, each task description solely consists of the patient's name and free text. Second, another demand posed by clinicians is to better align task management with healthcare process support (e.g., to keep track of medical orders) as well as integrated access to patient folders.

\subsection{Contribution}

This paper shows how such a process-aware, mobile task support has been realized in our $M E D o^{1}$ approach. The paper presents basic concepts as well as the information architecture underlying MEDo. Furthermore, it describes the methodology applied to design, develop and implement MEDo. We show in detail how requirements were elicited and in how our participation in different kinds of medical ward rounds contributed to this. Although MEDo focuses on the process-aware, mobile support of clincial tasks, we believe that similar solutions can be provided in the context of other knowledge-intensive processes as well.

This paper provides a significant extension of previous work we presented in [8]. In particular, in [8], we have neither provided fundamental insights into the method applied when developing MEDo nor the information architecture underlying MEDo. In addition, this paper provides an in-depth description of the phases of general ward rounds in hospitals in order to give detailed insights in real-world scenarios for mobile task and process management as well as existing challenges. While [8] only presents the ward rounds in internal and orthopaedic medicine, this paper additionally gives insights into ward rounds in trauma surgery and emergency. This includes a discussion of ward round characteristics as well as the way we addressed them in MEDo. For example, we provide an in-depth description of a ward round for which a mobile access to the hospital information system is already in use. Overall, the analysis of the four ward rounds has revealed that current approaches targeting at task and process support often neglect the way how clinicians organize their daily work. In particular, established working procedures, even those which more or less bypass the hospital information system, must be carefully analyzed and understood. We believe that such detailed insights are helpful to better understand the needs of knowledge-intensive processes in respect to mobile task support. Finally, we provide more details on features implemented by MEDo and discuss feedback of clinicians in this context.

The remainder of this paper is organized as follows: Section 2 summarizes the

${ }^{1}$ MEDo stands for MedicalDo. A video demonstrating MEDo can be viewed at: http://vimeo.com/channels/434999/54762040 
methodology we applied in the context of MEDo. In turn, Section 3 gives detailed insights into medical ward rounds and describes the method we applied to elicit fundamental requirements for a flexible support of medical ward rounds. In Section 4, we present these requirements in detail. Section 5 discusses the design, development and implementation of MEDo. In Section 6, we present results from applying MEDo in clinical practice and Section 7 summarizes evaluation results. Finally, Section 8 discusses related work and Section 9 concludes with a summary and outlook.

\section{Methodology}

Regarding the design of our research on mobile task support in the context of medical ward rounds, we consider two major aspects:

- Case Study: A detailed case study shall be conducted in order to properly understand how ward rounds are actually performed in clinical practice. In this context, the knowledge-intensive character of ward rounds shall be demonstrated and the understanding of knowledge-intensive processes in general be enhanced.

- Design Science: Based on the lessons learned from the case study, requirements are derived to design, develop, implement and validate an approach for mobile task support in the context of ward rounds. This approach shall be also assessed regarding its benefits in respect to the support of knowledgeintensive processes in other domains.

Overall, we choose and apply the following methodology (cf. Fig. 1) ensuring replicability and, hence, valid results.

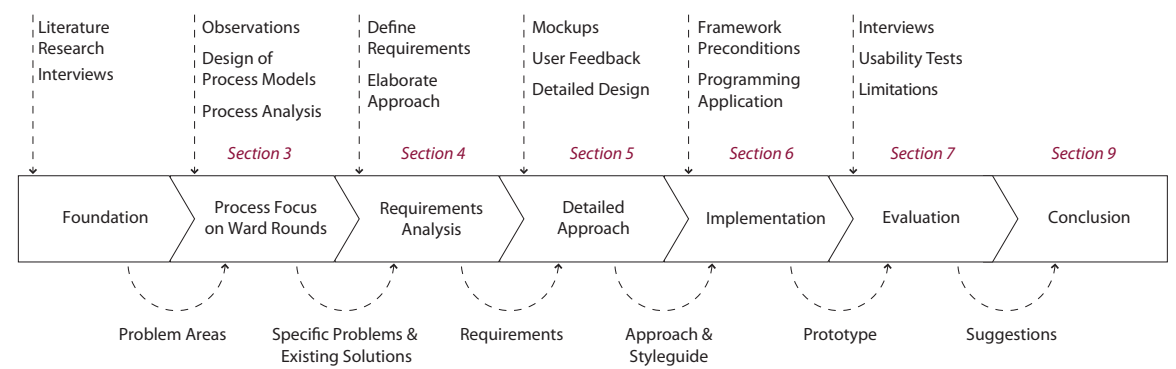

Fig. 1. Methodology

Our methodology comprises seven phases (cf. Fig. 1). In this paper, we present results of all phases (except the first one) in detail. In an initial phase, we analyzed existing work and interviewed clinicians from different medical disciplines (e.g., internal medicine and surgery). In particular, we wanted to elaborate 
major demands regarding mobile task support in the context of ward rounds. The results we obtained have confirmed that such a mobile task and process support is highly needed, but has not been properly addressed by existing approaches yet. All other phases are presented in the following. Furthermore, Section 5 refines our methodology to a more detailed level in order to indicate how the design and development of MEDo was accomplished in close interaction with clinicians.

\section{Medical Ward Rounds}

\subsection{General Procedure of a Ward Round}

Regardless of the medical discipline, the basic procedure of ward rounds in (German) hospitals is more or less the same. We sketch it and illustrate its major characteristics.

In general, a ward round comprises four phases (cf. Fig. 2).

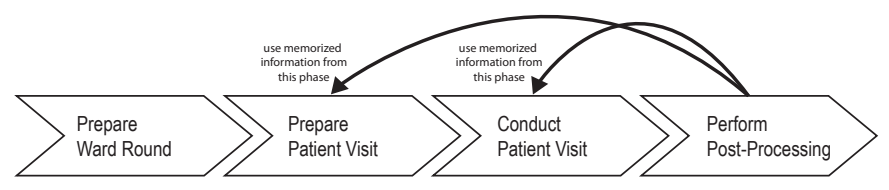

Fig. 2. Characteristic phases of a ward round

- Prepare Ward Round. In the preparation phase, patient data relevant for the ward round is gathered. This is either accomplished by nurses or assistant physicians. In turn, the collected data is then made available to medical staff depending on the IT infrastructure of the hospital. Usually, three options are common in practice: First, paper-based records are provided on a ward round trolley that is carried from room to room. Second, paper-based records are carried by the ward round team. Third, the ward round trolley is equipped with a computer enabling access to the hospital information system. In current practice, the second option is the predominant one.

- Prepare Patient Visit (Ante Portas). During this phase, the ward round team discusses the patient's health status outside the patient's room. If two or more patients are accommodated in the same room, their status is consequently discussed outside. This communication is either managed by a senior or an assistant physician responsible for the patient. Two kinds of medical orders may be made at this stage: First, orders may be assigned to nursing staff with the purpose to support the patient visit. Second, the physician may make notes about consultations required with other medical disciplines.

- Conduct Patient Visit. For each patient, the physician in charge decides whether or not the patient must be physically examined. Following this, medical findings are directly discussed with the patient. In particular, the 
patient is asked about current complaints. Finally, changes concerning the treatment of the patient are discussed and determined.

- Perform Post-Processing. In the last phase, the physician in charge reflects on the steps of the two preceding phases. Following this, she may schedule additional treatment procedures for the patients visited, i.e., she may sign medical orders (e.g., laboratory examinations) and external consultations, prescribe changes in medication, or make appointments with other experts (e.g., physical therapists). Note that this phase might be postponed to a later stage when exceptions occur or emergency situations interrupt the physician. As memorizing all information collected during the second and third phase is hardly possible, physicians rely on the (paper-based) documentation they made during the ward round.

\subsection{Observations}

We observed that frequently occurring exceptions, ad-hoc coordination efforts, and time pressure constitute major challenges for healthcare professionals in the context of their daily ward routines. Considering the high complexity and uncertainty of patient treatment processes (cf. Section 2), healthcare professionals rely on ward rounds as a reliable source regarding the current status of their inpatients [7]. Hence, a ward round is the common environment in which decisions about patient treatment can be synchronized and communicated, or changes in patient treatment (e.g., medications) be made. Considering this complexity and the tasks emerging in the context of ward rounds, clinicians have developed their own way for coping with uncertainty as well as the drawbacks of contemporary hospital information systems. In particular, the use of a paper-based task worksheet is an established practice for effectively organizing daily work. While paper-based worksheets show many advantages, a number of drawbacks can be observed as well:

- Using a task worksheet comprises two phases. In the first one, task acquisition is accomplished in order to prepare the second phase, during which the tasks are actually performed. In the first phase, problems might occur if the physician defining the task is not the same as the one making corresponding notes on a worksheet. In turn, the second phase reveals problems if task performance is done later, i.e., with a significant delay in relation to task acquisition. The most critical issue, we observed in this context, is loss of information.

- Before a shift change takes place, the physician in charge usually makes a neat copy for her colleague responsible for the next shift. On one hand, this way of handing over patient information shows several problems. For example, a physician may use her own "codes" for notes, which is not useful for the next physician in charge. Therefore, she changes her own codes in order to make them available for her colleague as well. On the other, this procedure is error-prone as well as time-consuming. 
- Handwritten notes might be unreadable or ambiguous, causing additional errors or at least time-consuming checks.

- The task worksheet is usually stored in the ward office to enable access to all ward members. As a result, physicians must visit the office in order to access the task worksheet. In turn, this is time-consuming and inefficient.

- Tasks and their status on paper-based worksheets are not traceable and the performed work can not be properly archived.

These obvious drawbacks have motivated our research. Section 3.3 gives detailed insights into four ward rounds we analyzed in different medical departments. Particularly, we discuss their characteristics and particularities in respect to the different medical disciplines they refer to.

\subsection{Ward Round Analysis}

We started our clinical investigations with an initial survey. In particular, we evaluated how physicians perceive the current management of ward rounds when using pen and paper. First, we studied how they perceive task acquisition. Second, we asked them how they currently manage ward rounds in general, i.e., how they handle communication with other healthcare professionals as well as the access to patient data provided by hospital information systems. Fig. 3 depicts the results of this survey. Later on, we will compare the use of pen and paper during ward rounds with the one of MEDo.

\begin{tabular}{lcc}
\hline Question & Mean Value & Standard Deviation \\
\hline Task Definition & 2.22 & 1.30 \\
Ward Round Management & 2.50 & 1.12 \\
\hline \multicolumn{2}{c}{ | Scale range has 6 values within the interval : very good - inadequate | } \\
\hline
\end{tabular}

Fig. 3. Task definition and overall ward round management without IT support

To elicit fundamental requirements and to better understand how these are currently addressed, we analyzed characteristic ward rounds. More precisely, we participated in four wards rounds at different clinical departments. The basic facts related to these ward rounds are summarized in Fig. 4. Interestingly, only one of the four clinical departments already provides an IT support for accessing patient data during ward rounds; i.e., imaging data and laboratory results may be accessed during ward rounds using a tablet PC. As can be seen from Fig. 4, the ward rounds we analyzed vary in respect to their basic characteristics.

Based on these insights, we extracted procedures performed or triggered in the context of a ward round. In particular, we were interested in how they can be smoothly integrated with mobile task support. Additionally, we identified patient data, physicians want to access in the context of their task lists.

In order to identify required procedures and needed patient data, we participated in the different ward rounds several times and then transferred the gained 
Pryss, Mundbrod, Langer, Reichert

\begin{tabular}{|c|c|c|c|c|}
\hline & Internal Medicine Ward & $\begin{array}{l}\text { Orthopaedic Ward } \\
\text { (paraplegic patients) }\end{array}$ & $\begin{array}{l}\text { Trauma Surgery Ward } \\
\text { (with head physician) }\end{array}$ & Emergency Ward \\
\hline Discussed in & Section 3.3.1 & Section 3.3.2 & Section 3.3.3 & Section 3.3.4 \\
\hline Hospital & University Hospital Ulm & Rehabilitation Hospital Ulm & University Hospital Ulm & University Hospital Ulm \\
\hline Number of Beds & 25 & 35 & $>100$ & 12 \\
\hline Average Period of & days, weeks & weeks, months & a couple of days up to & hours \\
\hline Hospitalization & & & one month & \\
\hline Frequency of Ward Rounds & twice a day & once a day & once a week & three times a day \\
\hline Purpose of Ward Round & daily overview & daily overview & $\begin{array}{l}\text { providing an overview } \\
\text { for the head physician on } \\
\text { all wards }\end{array}$ & $\begin{array}{l}\text { sharing information } \\
\text { with the team } \\
\text { responsible for the next } \\
\text { shift }\end{array}$ \\
\hline Involved Parties & $\begin{array}{l}\text { two ward physicians, } \\
\text { two nurses }\end{array}$ & $\begin{array}{l}\text { three ward physicians, } \\
\text { up to three nurses, } \\
\text { several therapists }\end{array}$ & $\begin{array}{l}\text { head physician, } \\
\text { substitute of head } \\
\text { physician, } \\
\text { ward physicians }\end{array}$ & $\begin{array}{l}\text { up to eight ward } \\
\text { physicians, } \\
\text { one senior physician, } \\
\text { additionally needed } \\
\text { experts (optional) }\end{array}$ \\
\hline $\begin{array}{l}\text { Visiting Time per Patient } \\
\text { (measured during investigation) }\end{array}$ & $\begin{array}{l}7+3.5 \text { minutes } \\
\text { (preparation+treatment) }\end{array}$ & 4 minutes & 3 minutes & 4 minutes \\
\hline Hospital Information System & ERP Software (SAP) & ERP Software (Meierhofer) & ERP Software (SAP) & ERP Software (SAP) \\
\hline \multicolumn{5}{|l|}{ Mobile Data Access to } \\
\hline Vital Data & $\checkmark$ (nursing documentation) & $\checkmark$ (nursing documentation) & $\sqrt{ }$ (nursing documentation) & $\checkmark$ (nursing documentation) \\
\hline Medication & $\checkmark$ (nursing documentation) & $\checkmark$ (nursing documentation) & $\checkmark$ (nursing documentation) & $\checkmark$ (nursing documentation) \\
\hline Imaging Diagnostics & $x$ & $\checkmark$ (tablet) & $\checkmark$ (printout) & $x$ \\
\hline Laboratory Findings & $x$ & $\checkmark$ (tablet) & $\checkmark$ (printout) & $x$ \\
\hline \multicolumn{5}{|c|}{$\mid(\boldsymbol{V})$ : available $\mid(\boldsymbol{X})$ : not available $\mid$} \\
\hline
\end{tabular}

Fig. 4. Basic facts characterizing four different ward rounds

insights to a more formal IT representation. In the latter context, explicitly defining the identified procedures in terms of BPMN process models has turned out to be useful. Thereby, a core set of BPMN elements has turned out to be sufficient for the discussions with clinicians. As a result of these discussions, relevant patient data physicians want to access is depicted in Fig. 5a. Additionally, Fig. $5 \mathrm{~b}$ shows the data privileges required by physicians and nurses in this context. Note that physicians emphasized the need to share task sheets with colleagues and nurses in order to improve overall communication.

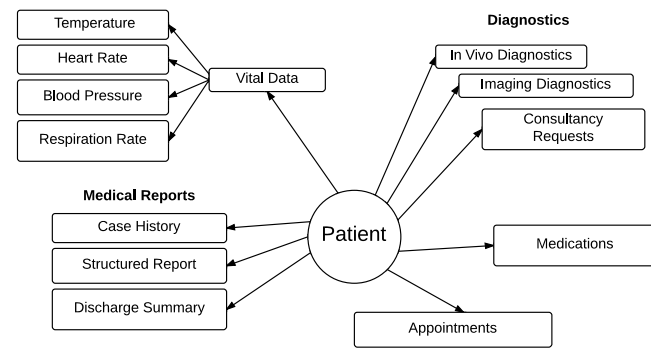

(a) Patient data

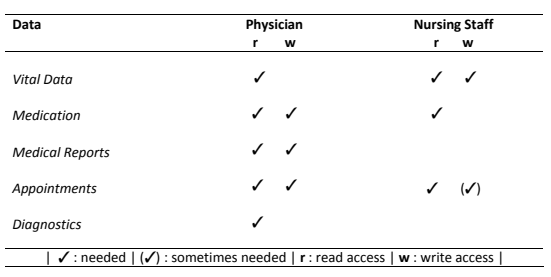

(b) Access privileges

Fig. 5. Patient data and access privileges 
In the following sections, we give insights into the ward rounds we investigated.

3.3.1 Ward Rounds in Internal Medicine Fig. 6 shows the process coordinating the steps of a ward round in a clinical department from internal medicine. This type of ward round is common to many hospitals encompassing two stages. Each of them comprises a number of tasks. In the first stage, the physician analyzes the cases of all inpatients without facing them immediately. For this purpose, he accesses the hospital information system in order to retrieve the information required. Furthermore, he is assisted by a nurse who provides him with relevant patient information as well. Finally, relevant issues and alternatives regarding patient treatment are discussed. In the second stage, the physician visits the inpatients, makes notes using pen and paper, and verifies her decisions. If new tasks (e.g., medical orders) become necessary, she makes a note on her worksheet and adopts this change in the hospital information system afterwards. Examples of tasks and medical orders, respectively, emerging in the context of the second stage include requests for X-ray examinations, laboratory tests, consultancies, and changes in patient medication. Making appointments with remote hospital departments constitutes another kind of task that might emerge during a ward round.

Compared to the other ward round scenarios, the internal medicine department must cope with larger numbers of orders per patient in the context of a ward round. Reason for this phenomenon is that inpatients are often multimorbid (i.e., patients suffering from multiple deceases). Hence, task worksheets based on pen and paper are crucial for effectively coordinating treatment changes during ward rounds. As a result, in internal medicine, physicians crave for a quick access to monitoring data during ward rounds (i.e., vital signs like pulse or oxygen level) using smart mobile devices. Note that the amount of data recorded per patient and day might be high. Anyway, it is indispensable for making decision during ward rounds. Another requirement raised by the physicians relates to the ability to access patient monitoring data in real time. Finally, in internal medicine only one physician usually performs the ward round. As a consequence, she must effectively hand over patient data to the next shift or to colleagues. Accordingly, any mobile assistance must consider this requirement.

3.3.2 Ward Rounds in Orthopaedic Medicine Fig. 7 shows the process coordinating the steps of a ward round in a clinical department from orthopaedic medicine. This ward round encompasses the stages described in the following. Before the ward round starts, in the first stage, one or more assistant physicians prepare relevant patient documents on a ward round trolley (e.g., X-rays or paper-based reports). In general, the ward round team consists of assistant physicians, a senior physician, and a physical therapist. In certain cases, the head physician participates as well. In the second stage, the following procedure is accomplished for each patient during the ward round. First, the patient situation is discussed outside his room based on the patient documents from the 


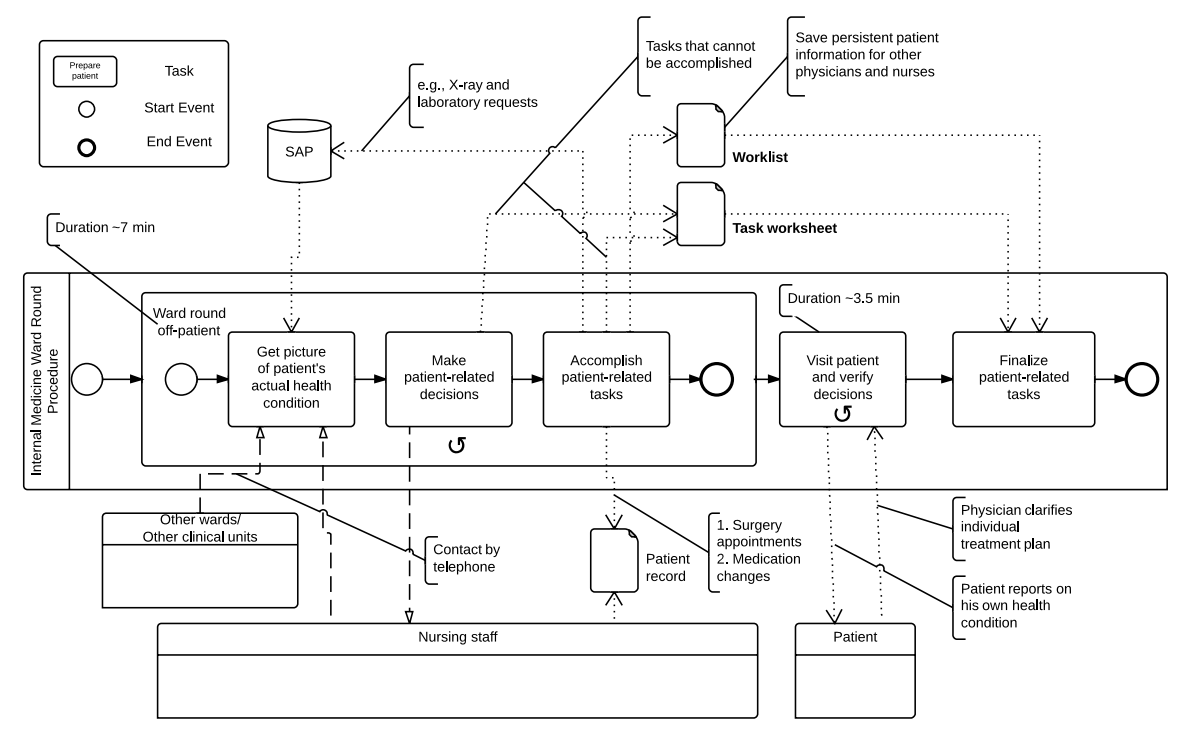

Fig. 6. Ward round in internal medicine

trolley. Second, the ward round team enters the room and a nurse determines the current vital signs of the patient. Meanwhile, the senior or head physician talks to the patient and decides about additional treatment.

Compared to the other scenarios, ward round management differs in one aspect: inpatients usually have a longer length of stay. Accordingly, the need to request additional examinations is high.

To minimize efforts for follow-up tasks, in the analyzed scenario a mobile access to the hospital information system has been already established. Interestingly, this mobile system does enable an access to the complete electronic patient record. Instead, the preparation of specific patient-related tasks can be accomplished using a tablet PC. In addition, the latter ensures mobile access to specific contents of the hospital information system.

Although the functions provided by the hospital information system have not been designed with the use of tablet PCs in mind and are hence not adequately mapped to the latter, physicians may order certain examinations through a mobile access to the hospital information system. Examples include request for $\mathrm{X}$-rays, and consultancies as well as changes in patient medication. Making appointments with physical therapists constitutes another important task to be accomplished by physicians. During a ward round, the senior or head physician makes notes about upcoming tasks, which are then processed by assistant physicians after the ward round. Recall that several documents related to these tasks may have already been prepared during the ward round. Therefore, mobile access to the hospital information system is leveraged enabling the physicians 
to quickly work on their tasks afterwards. Still, most orders are processed in a paper-based fashion.

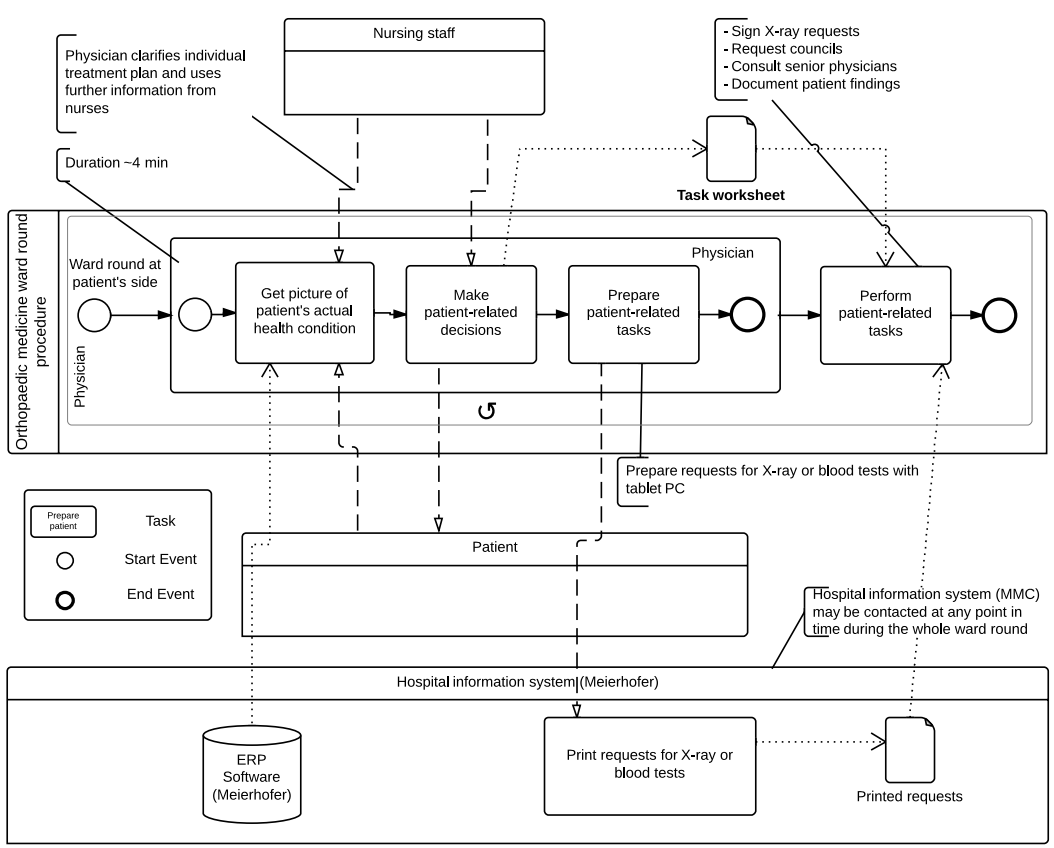

Fig. 7. Ward round in orthopaedic medicine

As a result, physicians considered the mobile acquisition of tasks and medical orders as being useful. Particularly, they emphasized that it contributed to reduce error rates (e.g., omissions). Again, the paper-based task worksheet constituted the most prevalent instrument for memorizing and communicating upcoming tasks. Furthermore, being already experienced with a mobile access to specific contents of the hospital information system, the physicians revealed a number of aspects they were still missing. First, the user interface of the mobile device was not properly mapped to the specific situation during a ward round. For example, context switches were not properly considered and task acquisition took too much time. Second, not all tasks could be captured using the mobile system, which resulted in a mixture of electronic and paper-based task notes. Third, no vital patient signs (e.g., heart rate, temperature, etc.) were displayed. Fourth, no status information about tasks concerning medication changes was provided by the mobile access to the hospital information system.

In the orthopaedic ward, we further observed a specific situation that we considered when designing MEDo [9]. In practice, a mobile access to the hospital information system with a tablet PCs is only possible if the respective hospital area provides a reliable wireless network. Actually, this has not been the case 
for one of the orthopaedic wards. Hence, the physicians of this ward could not use their tablet PC, but had to work with pen and paper worksheets instead. Accordingly, the setting of the orthopaedic ward allowed us to directly compare wards with and without mobile access to digital patient data. Fig. 8 presents obtained results [9].

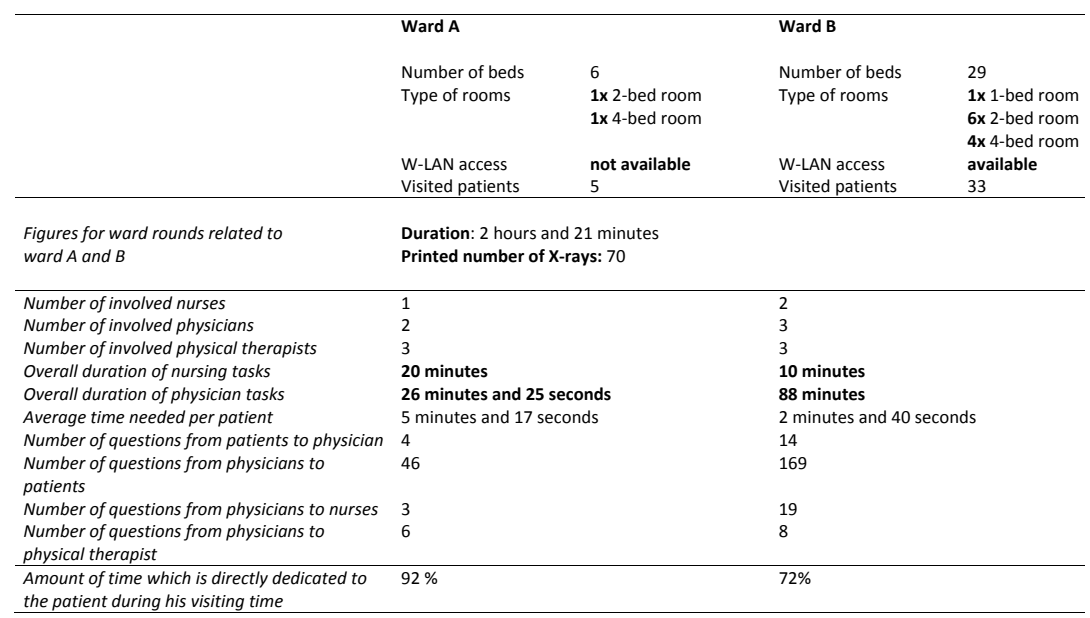

Fig. 8. Time measurements at two orthopaedic wards

Regarding Fig. 8, two issues are of particular interest in the context of our work. First, the average time needed per patient is decreasing for both physicians and nurses when using mobile devices. Second, the time directly dedicated to a patient (i.e., the physician is not distracted and talks with the patient) is decreasing when using a mobile device. While the first aspect shows that mobile assistance could relieve the medical ward round team in respect to task management, the second one indicates that such assistance might have drawbacks as well. Several patients pointed out that, even without the active usage of mobile devices during ward rounds, the physicians are somewhat distracted. Using mobile assistance bears the risk to further emphasize this drawback.

3.3.3 Ward Rounds in Trauma Surgery Fig. 9 shows the basic procedure of a ward round in trauma surgery. As a peculiarity, the head physician is present during the whole procedure. Usually, her attendance requires to visit all wards during a limited period of time due to a tight schedule. Interestingly, if the head physician is not present, only a subset of all wards is visited. In general, coordination efforts will increase if the head physician participates in the ward round. The reasons for this are as follows:

- More patient data must be prepared in advance. In turn, missing patient data would impair the ward round significantly. 
- The time that may be spend for a patient per average significantly decreases when visiting all wards during a limited time period.

- Changes related to patient treatment frequently become necessary. Taking the tight schedule into account, it is a challenging task to perform all medical orders effectively and accurately.

- During the ward round, a senior physician having specific knowledge about the respective patient case, might have to be consulted to discuss further treatment of the patient. If no senior physician is available, the respective post-procedure will be both time-consuming and error-prone.

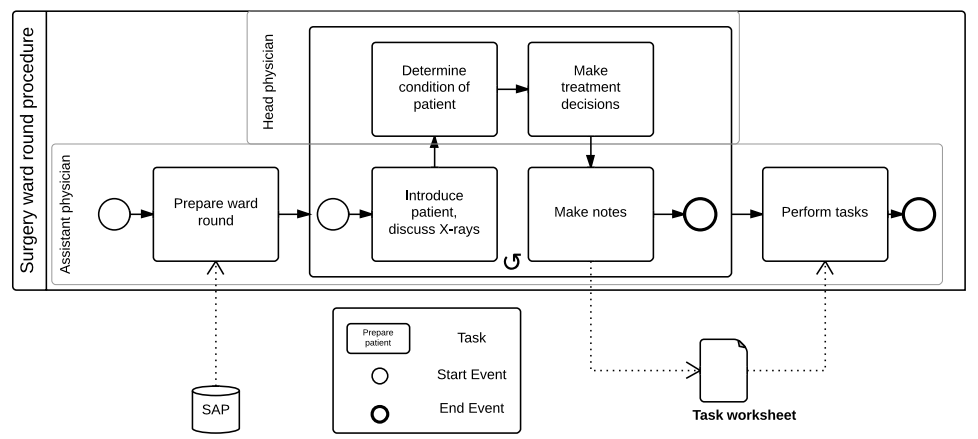

Fig. 9. Ward round in trauma surgery

The procedure of a surgery ward round is organized along the following stages: Before starting the ward round, in the first stage, assistant physicians prepare all relevant patient data. In particular, X-rays are needed for each patient. Since no mobile access to electronic patient data stored in the hospital information system is provided, X-rays are carried in paper-based form. For example, if four wards with 10 patients per ward must be visited, about $40 \mathrm{X}$-rays must be carried during the ward round.

After the preparation phase, in the second stage, the ward round starts. For each patient the procedure is the same. First, X-rays are discussed. Then, the head physician evaluates the patient's health status and decides about further treatment activities. Meanwhile, an assistant physician takes notes about orders and tasks using a pen and paper task worksheet. Tasks emerging in this context may refer to X-ray examinations, appointments with physical therapists, or lab tests. Particular attention will be required if a patient will undergo a surgery soon. For this case, it must be ensured that all tasks required for preparing the surgery are completed in time. In turn, all treatment changes, medical orders, and other tasks will be processed afterwards by one of the assistant physicians. 
Note that the assistant physician making the notes and the one performing the changes might be different persons. Worst case, the latter did not attend the ward round at all.

Furthermore, there was no mobile access to patient data during a surgery ward round. Since X-rays are usually captured in a digital format, accessing them by using mobile devices would ease the management of ward rounds. In addition, requesting X-rays using a mobile device was considered as fundamental requirement by the physicians we interviewed. Regarding task management, we observed that quick and easy task acquisition is crucial. We further observed, that in absence of the head physician, certain issues became easier to handle. Nevertheless, their handling based on pen and paper remains costly and errorprone.

As a result, the most important requirements with respect to mobile task support are as follows: physicians asked for a digital and mobile access to X-rays and wanted to be able to schedule X-ray examinations immediately at the patient's bedside. Finally, physicians wanted X-rays to be organized in folders style, which shall be easily browsable.

3.3.4 Ward Rounds in Emergency Medicine Fig. 10 shows the process coordinating the steps of a ward round in a clinical department from emergency department. This type of ward round shows specific characteristics that distinguishes it from the other three ward rounds we analyzed. Usually, patients stay in the emergency department only for a short period of time; afterwards they are either discharged or transferred to another ward. Although patients only have a short stay, they are visited at least twice during ward rounds. Considering the emergency situation of the patients, ward rounds take place at the beginning of a shift. We observed three specific aspects compared to the other ward rounds described.

- The situation of all patients is discussed when exchanging treatment details in the context of a shift change. Corresponding treatment changes are applied afterwards by the physicians who have just started their shift.

- For exchanging patient data among physicians, a whiteboard is used. This whiteboard allows exchanging patient information between different shifts. Further, it is used for making changes in patient treatment. Thereby, basic updates of patient data are made after a ward round including the option to erase data. Partial updates are made between two ward rounds. During this period, information may be added or pending tasks be marked as finished. No data may be erased from the whiteboard during this period.

- In many cases, patients staying at the emergency ward are sedated or narcotized, and hence are unable to communicate with physicians and nurses.

The emergency ward round comprises the following stages: In the first stage, an assistant physician collects data of all inpatients. Thereby, he may access three data sources. First, he may consult the whiteboard, which is updated after each ward round. Second, he uses his task worksheet. Third, he either may use 


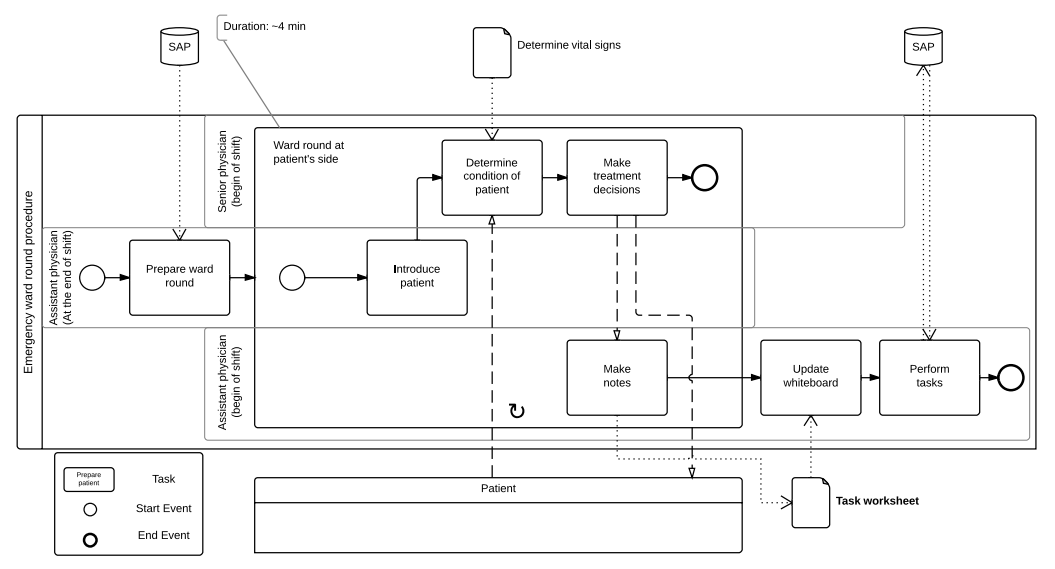

Fig. 10. Ward round in emergency medicine

patient data already transferred to the hospital information system or provided by the emergency medical services that transported the patient to the hospital. After the preparation phase, in the second stage, the ward round is performed by the physician who prepared it, a senior physician in charge, and all physicians taking over the shift. In this context, the senior physician is also responsible for treatment changes. Furthermore, he may order X-ray examinations, lab tests, and changes of the patient's medication. During this phase, the physicians having just started their shift are only observers. However, they will perform all acquired tasks afterwards and update the whiteboard accordingly.

As a result, physicians emphasized three crucial aspects to be considered when replacing their pen and paper task worksheet by a digital and mobile one. Most of them are related to the high coordination efforts and the rather critical situation of inpatients.

- Task acquisition must be easy and quick. In addition, it must be possible to prioritize tasks according to their importance.

- Gathering vital signs based on sensors (see [10] for a respective approach) and storing recorded data in an aggregated way on the task worksheet would be highly welcome by physicians. In addition, certain kinds of tasks should be automatically recommended to physicians based on the vital signs collected.

- The physicians crave for an easy and quick way to exchange patient data with colleagues from other shifts.

3.3.5 Discussion According to the ward round phases presented in Section 2, the results of our ward round analyses can be summarized as depicted in Figs. 11 and 12. We contrast the phases of the four ward rounds presented in this section. In turn, the obtained results provide the basis for designing MEDo and hence for replacing the paper-based task worksheet. 


\begin{tabular}{|c|c|c|}
\hline & Internal Medicine Ward & Orthopaedic Ward \\
\hline Prepare ward round & $\begin{array}{l}\text { One nurse } \\
\text { One physician } \\
\text { Access hospital information } \\
\text { system with a desktop } \\
\text { computer to organize tasks in } \\
\text { advance } \\
\text { Use ward round trolley with } \\
\text { paper-based documents }\end{array}$ & $\begin{array}{l}\text { One nurse } \\
\text { One physician } \\
\text { Prepare ward round } \\
\text { trolley with desktop } \\
\text { computer } \\
\text { Prepare mobile hospital } \\
\text { information system }\end{array}$ \\
\hline $\begin{array}{l}\text { Prepare patient visit } \\
\text { (ante portas) }\end{array}$ & $\begin{array}{l}\text { Not needed, only few } \\
\text { clinicians participate and } \\
\text { everything is prepared in } \\
\text { advance }\end{array}$ & $\begin{array}{l}\text { Senior or head physician } \\
\text { uses computer on the } \\
\text { trolley and additionally } \\
\text { gathers information from } \\
\text { ward team }\end{array}$ \\
\hline Visit patient & $\begin{array}{l}\text { Physician only makes notes } \\
\text { to those particular tasks, } \\
\text { using his paper-based task } \\
\text { worksheet, which must be } \\
\text { changed compared to the } \\
\text { preparation decision. He } \\
\text { must memorize what he has } \\
\text { done during preparation }\end{array}$ & $\begin{array}{l}\text { Senior or head physician } \\
\text { coordinates the patient } \\
\text { phase and uses a } \\
\text { combination of paper- } \\
\text { based worksheet and } \\
\text { mobile hospital } \\
\text { information system to } \\
\text { manage the patient } \\
\text { treatment }\end{array}$ \\
\hline Perform post-processing & $\begin{array}{l}\text { Task changes will be } \\
\text { performed in this phase } \\
\text { based on the worksheet }\end{array}$ & $\begin{array}{l}\text { Task, which cannot be } \\
\text { accomplished by mobile } \\
\text { hospital information } \\
\text { system must be } \\
\text { performed }\end{array}$ \\
\hline $\begin{array}{l}\text { Probability of delayed } \\
\text { performing of the post- } \\
\text { processing phase }\end{array}$ & high & low \\
\hline $\begin{array}{l}\text { Probability that the } \\
\text { physician who creates and } \\
\text { performs tasks differs }\end{array}$ & high & low \\
\hline Observed medical orders & $\begin{array}{c}\{\text { lab tests, consultations, } \\
\text { medication changes }\}\end{array}$ & $\begin{array}{c}\text { \{lab tests, medication changes, } \\
\text { X-ray examinations, } \\
\text { appointments with physical } \\
\text { therapists }\}\end{array}$ \\
\hline General issues & $\begin{array}{l}\text { Memorize task changes } \\
\text { No digital support during } \\
\text { patient phase }\end{array}$ & $\begin{array}{l}\text { Only partial access to hospital } \\
\text { information system with mobile } \\
\text { device }\end{array}$ \\
\hline $\begin{array}{l}\text { Main electronic worksheet } \\
\text { demands } \\
\text { (in order of importance) }\end{array}$ & $\begin{array}{l}\text { Provide status of medical orders } \\
\text { Provide hand over to next shift } \\
\text { Provide real-time vital signs }\end{array}$ & $\begin{array}{l}\text { Enable quick task acquisition } \\
\text { Provide status of medical orders } \\
\text { Provide real-time vital signs }\end{array}$ \\
\hline
\end{tabular}

Fig. 11. Analyses results for internal and orthopaedic wards

In particular, our case study revealed that quick task acquisition is demanded by all clinicians. Furthermore, except for the trauma surgery ward, all clinicians asked for a quick access to the status of their medical orders. Interestingly, the 
handling of orders only slightly differs between the different wards. Altogether, based on these insights and the experiences we made in the context of our case study, we are able to define fundamental requirements to be met by any mobile task support during ward rounds.

\begin{tabular}{|c|c|c|c|c|}
\hline & \multicolumn{2}{|c|}{ Trauma Surgery Ward } & \multicolumn{2}{|c|}{ Emergency Ward } \\
\hline Prepare ward round & $\checkmark$ & $\begin{array}{l}\text { One nurse } \\
\text { One physician } \\
\text { Collect all needed X-rays; } \\
\text { either they are printed or } \\
\text { the physician memorizes } \\
\text { information. } \\
\text { Collect laboratory results }\end{array}$ & $\checkmark$ & $\begin{array}{l}\text { One nurse } \\
\text { One physician } \\
\text { Memorize or copy } \\
\text { whiteboard information } \\
\text { Prepare ward round trolley } \\
\text { with desktop computer }\end{array}$ \\
\hline $\begin{array}{l}\text { Prepare patient visit } \\
\text { (ante portas) }\end{array}$ & $\checkmark$ & $\begin{array}{l}\text { Assistant physicians report } \\
\text { to senior or head physician } \\
\text { X-rays are not viewed in } \\
\text { this phase. }\end{array}$ & $x$ & $\begin{array}{l}\text { Tight time schedule and big } \\
\text { ward round team (new } \\
\text { shift is participating) makes } \\
\text { this phase impossible to } \\
\text { perform }\end{array}$ \\
\hline Visit patient & $\checkmark$ & $\begin{array}{l}\text { Senior or assistant } \\
\text { physician coordinates this } \\
\text { phase. All treatment } \\
\text { changes are documented } \\
\text { using the paper-based task } \\
\text { worksheet }\end{array}$ & $\checkmark$ & $\begin{array}{l}\text { Senior physician } \\
\text { coordinates this phase. An } \\
\text { assistant physician makes } \\
\text { notes on paper-based } \\
\text { worksheet }\end{array}$ \\
\hline Perform post-processing & $\checkmark$ & $\begin{array}{l}\text { All tasks related to patient } \\
\text { treatment will be } \\
\text { performed in this phase }\end{array}$ & $\checkmark$ & $\begin{array}{l}\text { All tasks related to patient } \\
\text { treatment will be } \\
\text { performed in this phase }\end{array}$ \\
\hline $\begin{array}{l}\text { Probability of delayed } \\
\text { performing of the } \\
\text { post-processing phase }\end{array}$ & & average & & high \\
\hline $\begin{array}{l}\text { Probability that the } \\
\text { physician who creates and } \\
\text { performs tasks differs }\end{array}$ & & average & & high \\
\hline Observed medical orders & $\begin{array}{r}\{\text { lab } \\
\text { ray } \\
\text { a }\end{array}$ & $\begin{array}{l}\text { tests, medication changes, } \mathrm{X} \text { - } \\
\text { examinations, consultations, } \\
\text { ppointments with physical } \\
\text { therapists }\end{array}$ & $\begin{array}{l}\{\text { lab } \\
\text { ray }\end{array}$ & $\begin{array}{l}\text { tests, medication changes, } \mathrm{X} \text { - } \\
\text { examinations, consultations }\end{array}$ \\
\hline General issues & & $\begin{array}{l}\text { No digital access to X-rays } \\
\text { digital access to laboratory }\end{array}$ & & $\begin{array}{l}\text { hange information between } \\
\text { three different media }\end{array}$ \\
\hline $\begin{array}{l}\text { Main electronic worksheet } \\
\text { demands } \\
\text { (in order of importance) }\end{array}$ & & $\begin{array}{l}\text { nable quick task acquisition } \\
\text { ovide digital access to X-rays } \\
\text { Provide digital access to } \\
\text { laboratory }\end{array}$ & & $\begin{array}{l}\text { lable quick task acquisition } \\
\text { rovide real-time vital signs } \\
\text { jide status of medical orders }\end{array}$ \\
\hline
\end{tabular}

Fig. 12. Analyses results for trauma surgery and emergency wards 


\section{Requirements for Mobile Task and Process Assistance}

This section summarizes the major requirements that can be derived from our case study, i.e., from the analysis of the four ward rounds. First, we discuss the requirements related to digital task creation and management. Second, we discuss requirements of the processes supporting mobile task management.

\subsection{Task Creation and Management}

We first summarize requirements raised by physicians with respect to digital worksheets enabling mobile task management. Usually, physicians and nurses organize their daily tasks based on paper worksheets. Thereby, task definition is accomplished the same way. For example, physicians make handwritten notes on their worksheet. In turn, each of these notes consists of a patient name and descriptive text. Creating and managing tasks this way means working quickly and being flexible. Thus, tasks may be acquired in different context, while task acquisition may be interrupted at any time. Exactly these two aspects have been mentioned by physicians as major reasons for still using pen and paper. Hence, when transferring task management to a mobile IT application, we must ensure that its use is time-efficient, intuitive, and offers the same flexibility as pen and paper. Note that no mobile task support will be accepted by medical staff if its use is more cumbersome and time-consuming than just using paper-based worksheets. Fig. 13 summarizes major requirements in respect to mobile task creation and management.

\begin{tabular}{|c|c|c|}
\hline & Task Requirements & Description \\
\hline $\mathbf{R}_{\mathbf{1}}$ & Manage the task digitally with mobile assistance & $\begin{array}{l}\text { Provide patient's name and free text to physicians in order to } \\
\text { manage their digital task entries (todo-items) comparable to } \\
\text { that of pen and paper. }\end{array}$ \\
\hline $\mathbf{R}_{\mathbf{2}}$ & Access patient information properly & $\begin{array}{l}\text { Provide quick access to patient data, e.g., vital data, medical } \\
\text { reports, external appointments, medications, and } \\
\text { diagnostics. }\end{array}$ \\
\hline \multirow[t]{4}{*}{$\mathbf{R}_{\mathbf{3}}$} & Ensure a high input speed for task acquisition & Enable a high input speed for task definition. \\
\hline & $\mathbf{R}_{\mathbf{3 1}}$ Provide text templates for task creation & $\begin{array}{l}\text { Provide pre-defined text templates to physicians for creating } \\
\text { tasks quickly. }\end{array}$ \\
\hline & $\mathbf{R}_{\mathbf{3 2}}$ Enable voice recording for task creation & $\begin{array}{l}\text { Provide a voice recording feature to physicians for defining } \\
\text { tasks comfortably. }\end{array}$ \\
\hline & $\mathbf{R}_{\mathbf{3 3}}$ Enable creation of new text templates & $\begin{array}{l}\text { Enable physicians to create new or personally tailored text } \\
\text { templates. }\end{array}$ \\
\hline $\mathbf{R}_{4}$ & $\begin{array}{l}\text { Enable barcode scanning for medications, plasters, } \\
\text { bandages, and so forth }\end{array}$ & $\begin{array}{l}\text { Provide a barcode feature to scan medications, plasters, } \\
\text { bandages, or to dress material used for patients. }\end{array}$ \\
\hline $\mathbf{R}_{\mathbf{5}}$ & Provide filter functions for tasks & $\begin{array}{l}\text { Provide a filter function to save time while managing task } \\
\text { entries. }\end{array}$ \\
\hline $\mathbf{R}_{6}$ & Organize tasks according to their importance & $\begin{array}{l}\text { Provide physicians with a feature to organize tasks according } \\
\text { to their importance. }\end{array}$ \\
\hline
\end{tabular}

Fig. 13. Requirements for mobile task management

When meeting the requirements summarized in Fig. 13, tasks can be created quickly. Furthermore, task management and patient data can be properly integrated. However, when building our first MEDo prototype, it turned out that 
task acquisition had been perceived as not being fast enough. To reach a level of usability comparable to that of pen and paper, therefore, additional improvements became necessary (cf. Requirements $R_{31}-R_{33}$ in Fig. 13). Among others, we realized a collection of text templates that may be used for creating tasks digitally. Our tests with clinicians have shown that these text templates have increased task acquisition speed significantly. Furthermore, tasks may be acquired and created using a voice recording feature, which we integrated with MEDo as well.

\subsection{Process Management}

Flexible process support (see [11] for a survey of existing concepts and techniques) is another key requirement raised by physicians. By integrating mobile task assistance with process support, it shall become possible to keep track of the status of their tasks (e.g., medical orders), to get aggregated overview lists, or to receive immediate notifications if a problem occurs. For example, the status of an X-ray order or blood examination, requested during a ward round, can be easily monitored based on corresponding processes. Figs. 14 and 15 depict examples of characteristic processes we identified in this context.

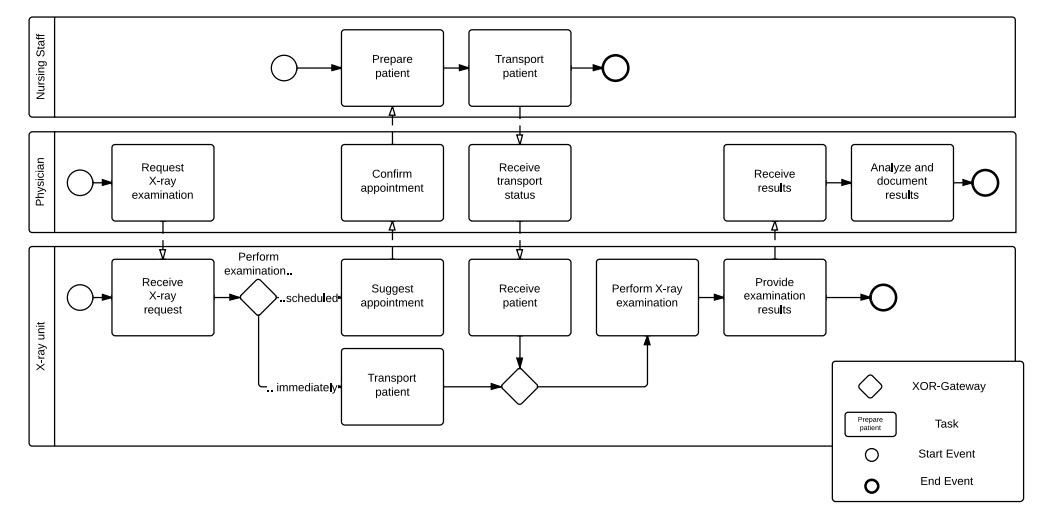

Fig. 14. Process for handling X-ray examinations

Regarding process-based task support, we gathered three major requirements from physicians. First, they require a quick overview of their tasks and related processes $\left(c f . R_{9}\right)$. Second, these processes shall be automatically triggered and be properly coordinated by a process-aware hospital information system after creating respective tasks (cf. $R_{7}$ ). Third, the current state of a task and its underlying process, respectively, shall be accessible and changeable based on different user screens (cf. Requirements $R_{8}$ and $R_{9}$ ). For example, if the results of a lab test order arrive, the physician shall get immediate access to them. Afterwards, he may want to directly change the state of this task and its related 


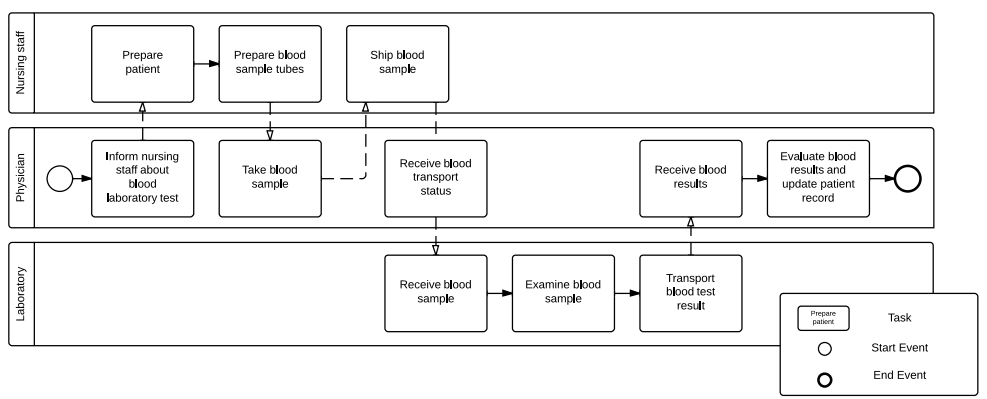

Fig. 15. Process for handling blood examinations

process to "seen". In particular, such an interaction must be possible via different user screens. For example, a physician may want to change the status of her task by either using the task overview or the laboratory screens. Fig. 16 summarizes the requirements related to such a process-aware task support.

\begin{tabular}{lll}
\hline & Process Requirements & Description \\
\hline $\mathbf{R}_{\mathbf{7}} \quad \begin{array}{l}\text { Use processes to coordinate the processing of a task } \\
\text { and to keep track of their status }\end{array}$ & $\begin{array}{l}\text { Support processes for handling and processing tasks. } \\
\text { Integrate these processes smoothly with the hospital } \\
\text { information system. } \\
\text { The processes as well as the user interface must properly } \\
\text { support healthcare professionals in interrupting their current } \\
\text { work at any point in time and continuing it later on. } \\
\mathbf{R}_{\mathbf{8}} \quad \text { Allow interrupting tasks and continuing them later } \\
\text { Processes should be intuitively presented to healthcare } \\
\text { professionals. }\end{array}$ \\
$\mathbf{R}_{\mathbf{9}} \quad$ Provide proper views on processes to the user &
\end{tabular}

Fig. 16. Process requirements

\section{Designing, Developing and Implementing MEDo}

Drawing upon the presented requirements, we sketch the procedure applied for designing, developing and implementing MEDo. In particular, we detail the second part of the methodology presented in Section 2. Fig. 17 shows this procedure and its seven steps.

In the first step, we elaborated task management scenarios together with physicians and nurses. Thereby, the results of the ward round investigation phase were incorporated, i.e., the created process models constituted an important basis for discussing relevant issues with physicians and nurses. Based on the insights we gained from these discussions, the decision for a high-fidelity prototype representing the first MEDo application was made in a second step. Such prototypes are functionally similar to a final application and already implemented on the target platform. Regarding the latter, we evaluated existing mobile tablet PC frameworks to select one, meeting the requirements of clinicians best. In this 


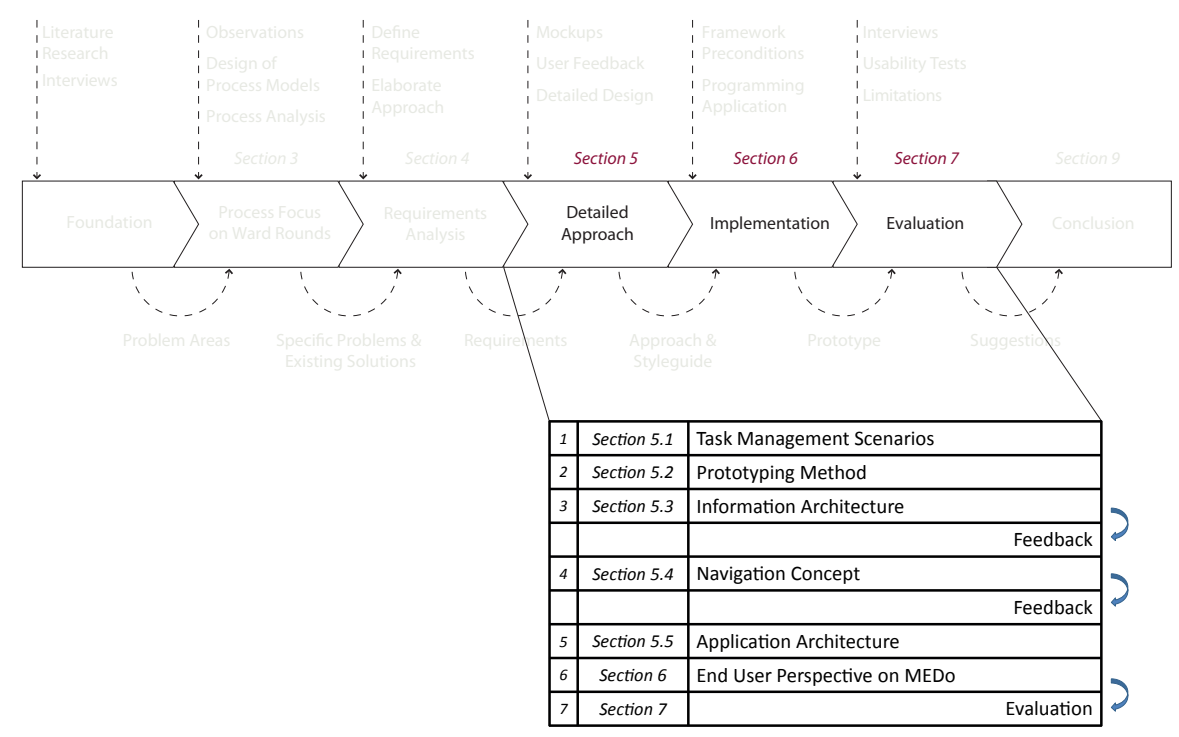

Fig. 17. Designing, developing and implementing MEDo

context, aspects like size, weight, display resolution, viewing angle dependency, usability and input sensibility were considered. Taking these properties into account, we decided to develop MEDo for the iPad. In a third step, the overall information architecture for MEDo was designed, determining which activities are provided by the application (i.e., control flow structure). To validate this architecture, we provided it to the medical staff and asked for feedback. Afterwards, we designed mockups for MEDo's navigation concept and screen design based on the developed information architecture. Following this, we discussed the mockups with physicians and nurses in order to obtain feedback from them. In this phase, several cycles have become necessary in order to meet the clinicians' requirements. In a fifth step, we designed the final architecture and functionality of MEDo. Sixth, we implemented the MEDo prototype for the iPad. Finally, we evaluated the resulting prototype with physicians and nurses.

Due to lack of space, we only present selected aspects of the explained procedure in detail. We focus on aspects important for understanding MEDo. Finally, we emphasize particular challenges that emerged when implementing MEDo.

\subsection{Task Management Scenarios}

In order to identify a minimal set of needed screens, we identified and analyzed frequent task management scenarios covering task acquisition, types of tasks, task execution, and situations demanding context switches. Fig. 18 exemplarily depicts five of these scenarios in which tasks are primarily created and inspected. Altogether, we identified 20 different scenarios in this context. 


\begin{tabular}{|c|c|}
\hline Scenario & Description \\
\hline Scenario I & $\begin{array}{l}\text { Before entering the room of a patient during a ward round, a physician wants to get a quick overview } \\
\text { of all examination results that have recently arrived as well as the overall health condition of the } \\
\text { patient. Therefore, she uses the MEDo screen shown in Fig. } 26 \text {. }\end{array}$ \\
\hline Scenario II & $\begin{array}{l}\text { After a ward round, the physician wants to see all upcoming tasks of the day at a glance. He then uses } \\
\text { this overview for planning his work day (cf. Fig. 27a). }\end{array}$ \\
\hline Scenario III & $\begin{array}{l}\text { During a ward round, the physician wants to know whether an X-ray examination has already been } \\
\text { requested and what status the examination currently has. Fig. } 27 \mathrm{~b} \text { indicates that the X-ray has arrived } \\
\text { and the physicians may finish the process by setting the state to Mark as seen. }\end{array}$ \\
\hline Scenario IV & $\begin{array}{l}\text { During a ward round, a set of tasks shall be created. Often, a particular physician makes orders, while } \\
\text { another one is collecting them. Fig. } 28 \text { a shows the creation of a task using text templates, whereas } \\
\text { Fig. } 28 \text { b shows the creation of a laboratory request using a specialized laboratory creation screen }\end{array}$ \\
\hline Scenario V & $\begin{array}{l}\text { During a ward round, a physician wants to use the voice recording feature of her tablet PC to quickly } \\
\text { create a task (cf. Fig. 28a). }\end{array}$ \\
\hline
\end{tabular}

Fig. 18. Examples of task management scenarios

\subsection{Prototyping Method}

In usability engineering, two different ways of prototyping can be differentiated in principle: low- and high-fidelity prototyping [12]. While the first one is often defined by pen and paper or coarse-grained digital representations, the latter targets more on details - like a final application. A lesson we had learned in previous projects is that experiences with smart devices like tablet computers can hardly be imagined by clinicians. Since we had not found any comparable studies about the usage of contemporary smart devices in clinical environments, we preferred designing a high-fidelity prototype for obtaining more profound feedback on our approach and to provide a working experience similar to the final application. While working on task management scenarios with medical staff, we had learned that two particular perspectives need to be implemented: a patient-data perspective and a combined task process perspective. As a result, in addition to the basic screen and navigation concept, we implemented a basic patient data management and a lightweight process engine with MEDo. Finally, usability can be improved when making use of results from cognitive science and applying design techniques from usability engineering, like choosing the right colours or realizing a comprehensible and useful segmentation of the application screen. Both interviews and usability tests with medical staff helped us to figure out which user interface elements are intuitive for them.

\subsection{Information Architecture}

A fundamental aspect of any mobile smart device application is its information architecture, i.e., the fundamental control flow structure of its user interface. For example, in our context, it is crucial to allow medical staff members to interrupt the processing of a task at any point in time and to continue it later. Therefore, users should be enabled to switch between different screens of the mobile application. Next, we utilized the collected task management scenarios (cf. Section 5.1) in order to define the basic functions to be covered by MEDo and its information architecture (cf. Fig. 19). In this context, functions IAF $_{1^{-}}$ $\mathrm{IAF}_{3}$ refer to the collaboration among medical staff members in the context of 
medical tasks. Obviously, collaboration is crucial during ward rounds and hence should be smoothly integrated with any task management component.

\begin{tabular}{lll}
\hline & Information Architecture Functions & Description \\
\hline $\mathbf{I A F}_{1}$ & Share the task list with other physicians and nurses & Share tasks with other physicians and nurses. \\
$\mathbf{I} \mathbf{A F}_{\mathbf{2}}$ & Provide a multi-user mode for tasks & Provide different screens for physicians and nurses. \\
$\mathbf{I} \mathbf{A F}_{3}$ & $\begin{array}{l}\text { Consider task lists when switching between two } \\
\text { shifts }\end{array}$ & $\begin{array}{l}\text { Electronic worksheets have to be easily handed over } \\
\text { between the staff of a shift. }\end{array}$ \\
$\mathbf{I A F _ { 4 }}$ & $\begin{array}{l}\text { Provide the user with special screens showing } \\
\text { upcoming tasks }\end{array}$ & $\begin{array}{l}\text { The handling of upcoming tasks shall be eased. Access to } \\
\text { them must be quick and easy. }\end{array}$ \\
$\mathbf{I A F _ { 5 }}$ & $\begin{array}{l}\text { Provide the user with screens summarizing } \\
\text { examination results }\end{array}$ & $\begin{array}{l}\text { A fast and adequate access to examination results is } \\
\text { required. }\end{array}$ \\
\hline
\end{tabular}

Fig. 19. Information architecture functions

Based on these insights, we came to the conclusion that tasks shall constitute the predominant paradigm for user interaction in MEDo's information architecture (cf. Fig. 20). Therefore, a physician does not need to switch screens if she wants to create a new task, but she can do this at any point during interaction. For instance, a request for an X-ray examination may be entered using the task screen or alternatively through every other screen (e.g., the screen showing a patient's lab results).

\subsection{Navigation Concept}

An information architecture defines the user screens to be designed and implemented as well as the control flow between them. In order to illustrate how we designed this information architecture, we present selected aspects of the patient screen. The first issue to be addressed concerns the visual design and layouting of the screen. Since different types of patient information shall be displayed, a proper design is crucial for later user acceptance. Together with physicians and nurses, we elaborated three different options how this patient screen may look (cf. Fig. 21). After discussing the options with the clinicians, it turned out that the third one fits best to their needs (see the arrow marked with 3 in Fig. 21). In particular, they perceived this option as the most intuitive one since it is similar to a paper-based patient record. In turn, in order to properly realize this design, we decided to use tabs for accessing the different kinds of patient information (e.g., laboratory, vital signs, and medical reports).

Our first mockup related to tabs is depicted in Fig. 22. Note that we use one mockup to illustrate tabs in general and one to show how tabs can be realized on an iPad. By default, tab controls are placed on the bottom of an iPad screen. Clinicians perceived this tab positioning as not being very useful. Taking their feedback into account, we designed tab controls in a different way according to the mockup shown in Fig. 23. As a result, we had to implement new tab control elements for MEDo. 


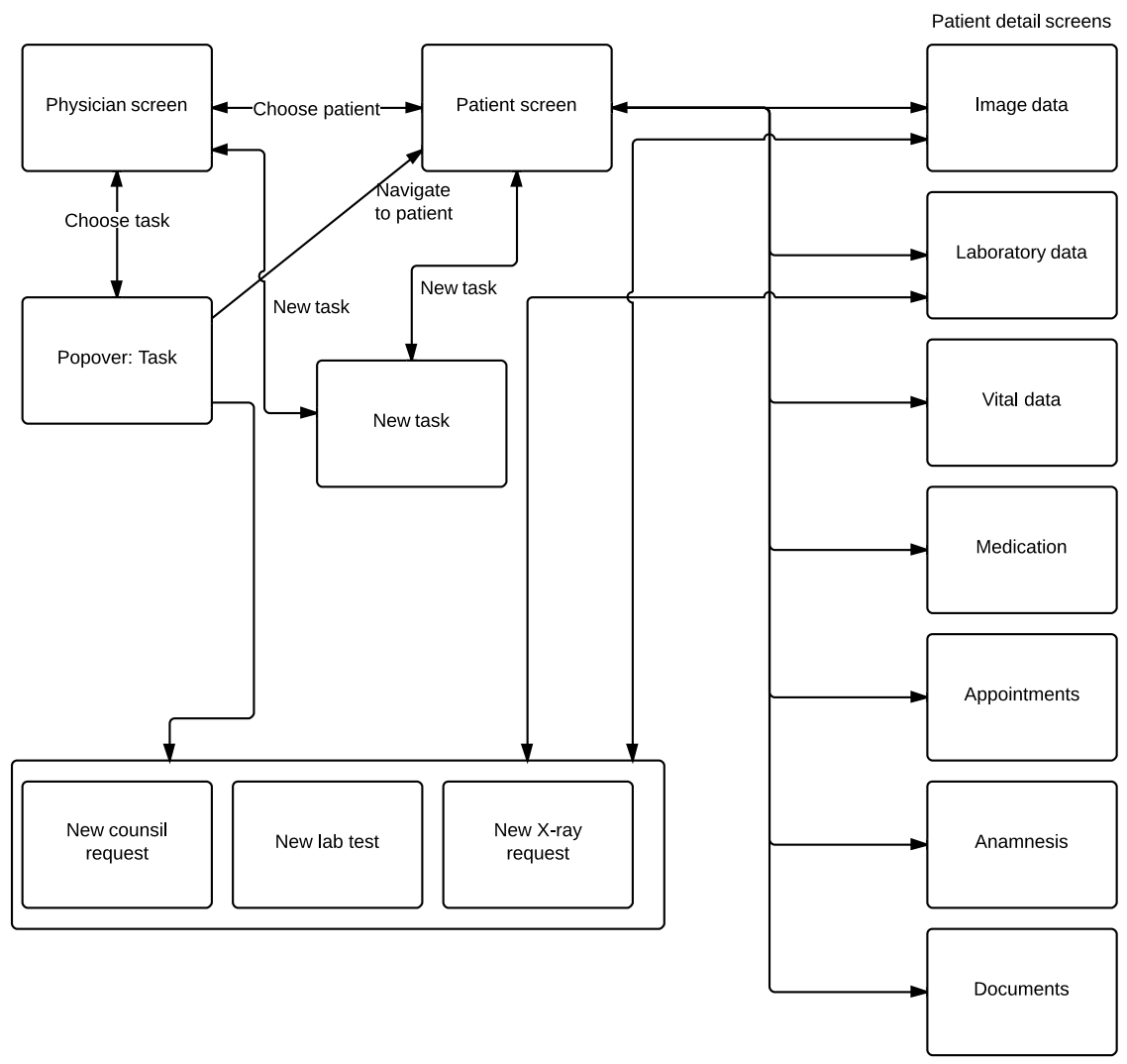

Fig. 20. MEDo information architecture

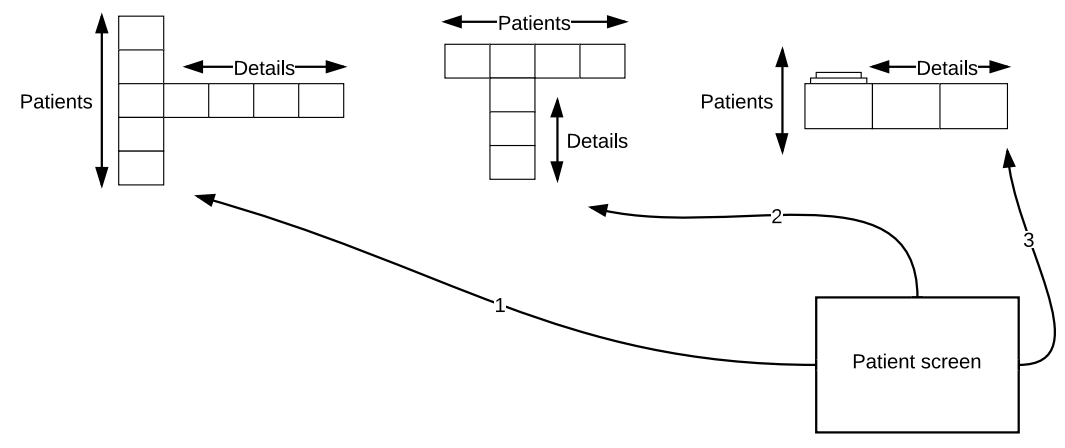

Fig. 21. Patient screen options 


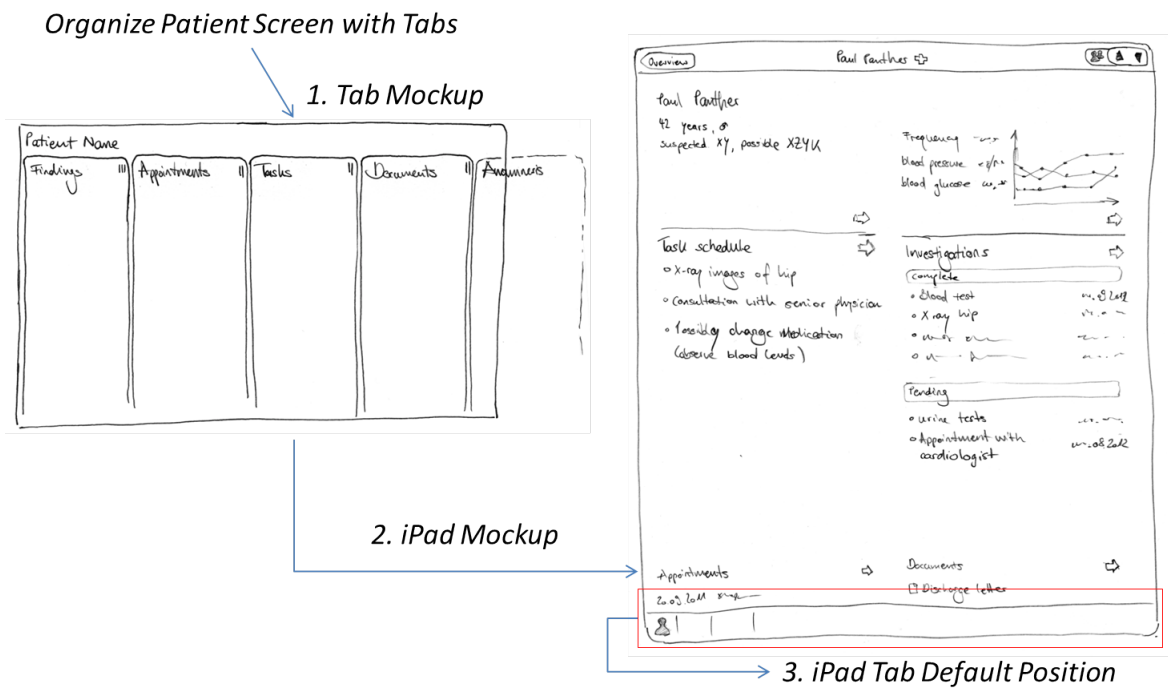

Fig. 22. First mockup of a patient screen with tabs

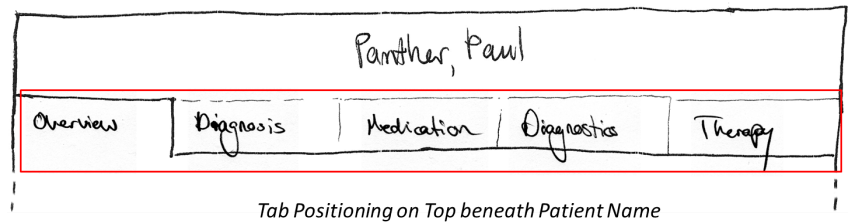

Fig. 23. Final mockup of a patient screen with tabs

In general, every MEDo screen was designed and implemented stepwise through feedback provided by ten clinicians ( 3 male and 3 female physicians; 4 nurses). Altogether, it took us two months to accomplish this design of the MEDo approach. In future work, we will also measure how long physicians and nurses spend on working with the different screens in order to enhance overall usability.

\subsection{Application Architecture}

As described in Section 5.2, MEDo contains a basic patient data management as well as a lightweight process engine. For this purpose, a data model provides a solid foundation. Fig. 24 exposes this data model featuring different semantic areas: data related to task and process management, data related to patients, and data related to ward and user management.

Regarding the implemented process engine, we only present selected aspects due to lack of space. Fig. 25 depicts the interface of the engine as well as an XML snippet showing a process definition in MEDo. 


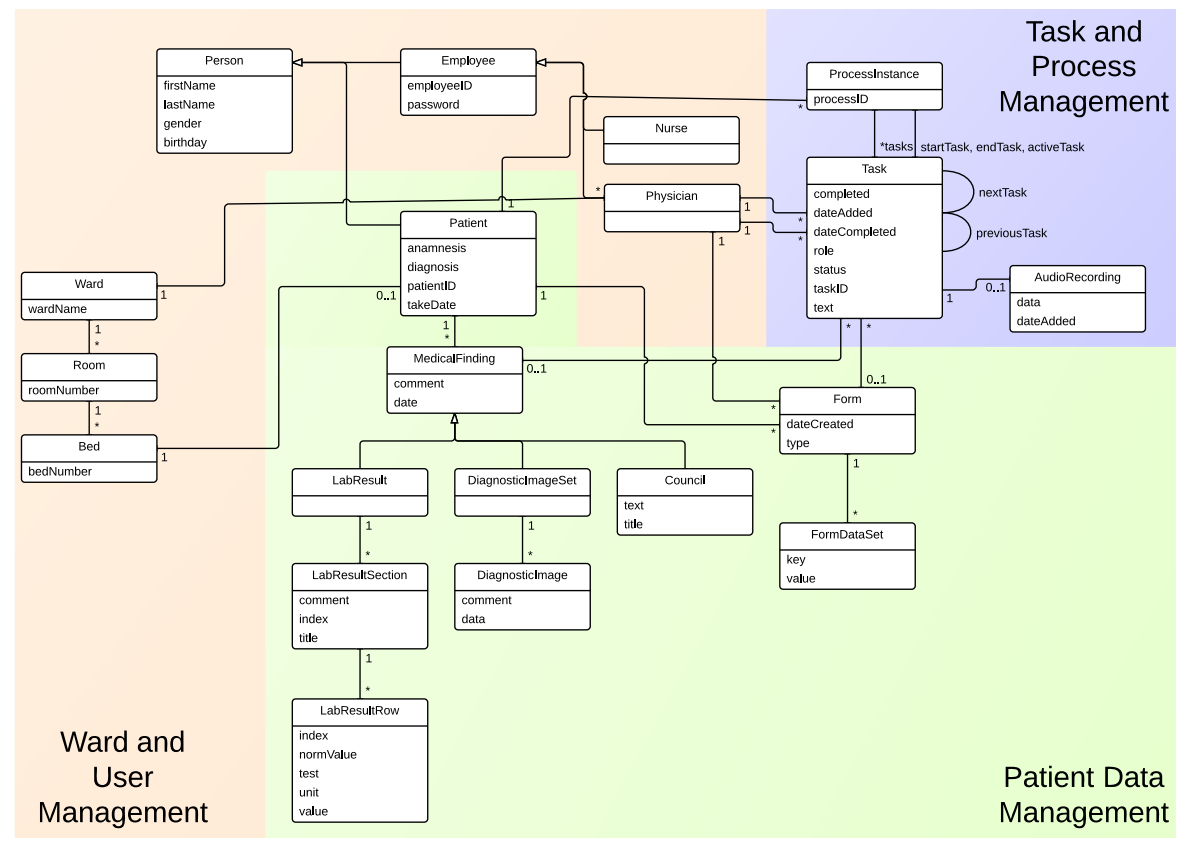

Fig. 24. MEDo data model

A MEDo process comprises three important components: phrases, tasks, and actions. Phrases identify a particular process. Hence, if a physician uses one of these phrases, the respective process will be started. Then, the tasks will be performed in sequence as defined (i.e., from the top to the bottom). Finally, the action command allows interrupting users to display a pop-up screen. In response to that, a user must actively confirm the action. Note that this feature has been rated as quite important by clinicians.

\section{End User Perspective on MEDo}

To give an idea how MEDo works in practice, we present selected features. For this purpose, we introduce user interface screens related to the scenarios we described in Fig. 18 and discuss how they have been realized in MEDo. Regarding Scenario I (cf. Fig. 18), Fig. 26 shows a screen displaying all relevant information about a particular patient at a glance. This screen was used by physicians most often when using MEDo. Physicians pointed out that getting such an overview at a glance is very crucial for them. Further, they confirmed that the option to quickly switch to a particular patient screen is very useful for their daily routines. Fig. 27a shows the MEDo entry screen and Marking 1 refers to the list of all patients. In MEDo, patients may either be listed alphabetically or according to the rooms they are assigned to. 


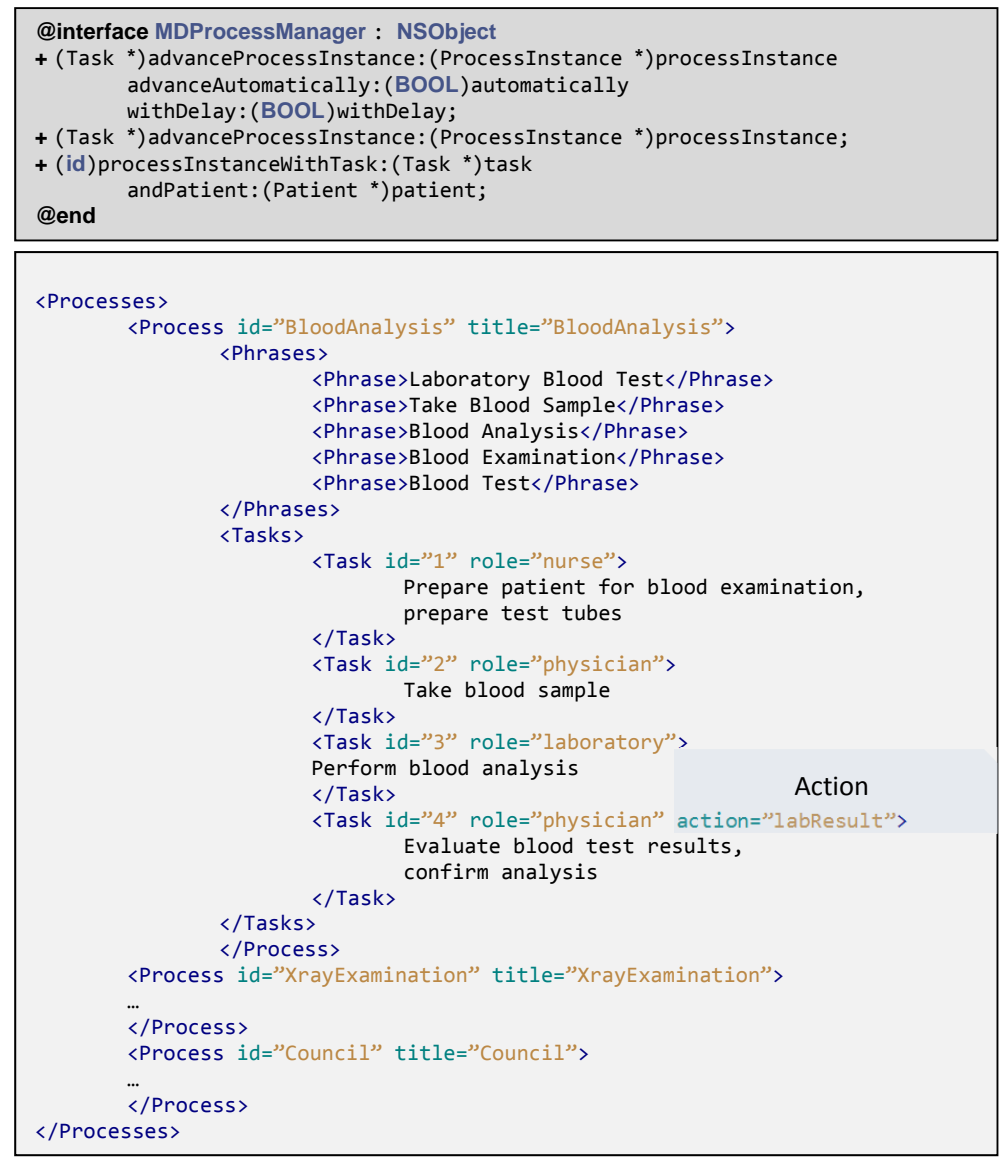

Fig. 25. MEDo XML process definition

In Fig. 27a, Marking 2 refers to both upcoming and recently completed tasks. This screen is used by the physicians in the context of Scenario II (cf. Fig. 18). In turn, Marking 3 shows the processing state of a selected task (X-ray request). For example, when an X-ray image arrives, a respective symbol indicates the status change to the physician. In order to study the results obtained, in turn, the physician may switch to the imaging screen (cf. Fig. 27b). Marking 4 refers to an element allowing the physician to change the state of the X-ray request to "finished" (cf. Scenario III in Fig. 18). Accordingly, the corresponding process completes. In Fig. 28a, Marking 5 shows the pre-defined text templates, the physician may use when defining a task (cf. Scenario IV in Fig. 18). Note that this feature has turned out to increase task acquisition speed significantly. In addition, related processes can be automatically derived from task definitions based on the text templates provided. For instance, if a physician uses text template Request Council for defining a task, a corresponding process will be started 


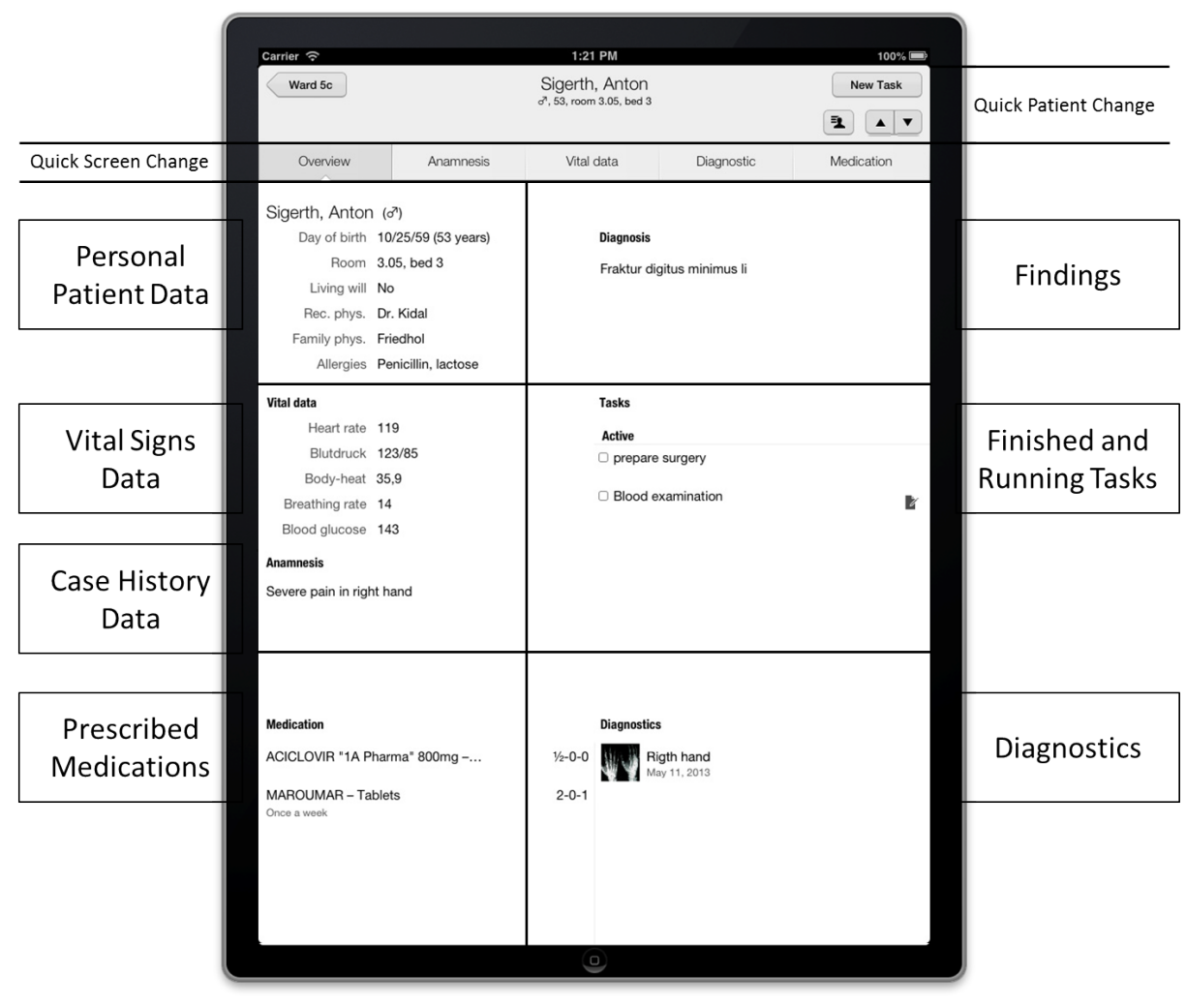

Fig. 26. Patient detail screen

in the background. In addition to text templates, a voice feature has been integrated (cf. Marking 6), i.e., the physician may use her voice for recording tasks (cf. Scenario $V$ in Fig. 18). However, it is not yet possible to derive respective processes directly from these voice recordings. Fig. $28 \mathrm{~b}$ depicts the form of a lab test order (cf. Scenario IV in Fig. 18).

Marking 7 exemplarily shows different ways of creating tasks in the context of the laboratory screen. When interviewing medical staff, we analyzed how many task creation buttons are useful for a particular MEDo screen and how they shall be positioned on it. Moreover, the user interface was optimized in several cycles based on the feedback provided by medical staff. Finally, Fig. 29 shows how to use the action command of the process engine (cf. Fig. 29a) and how to smoothly switch between different patients (cf. Fig. 29b). In detail, in Fig. 29a, a physician must confirm the results of a blood examination, while in Fig. 29b, he may access the list in the patient screen to see to which patients he may switch. 


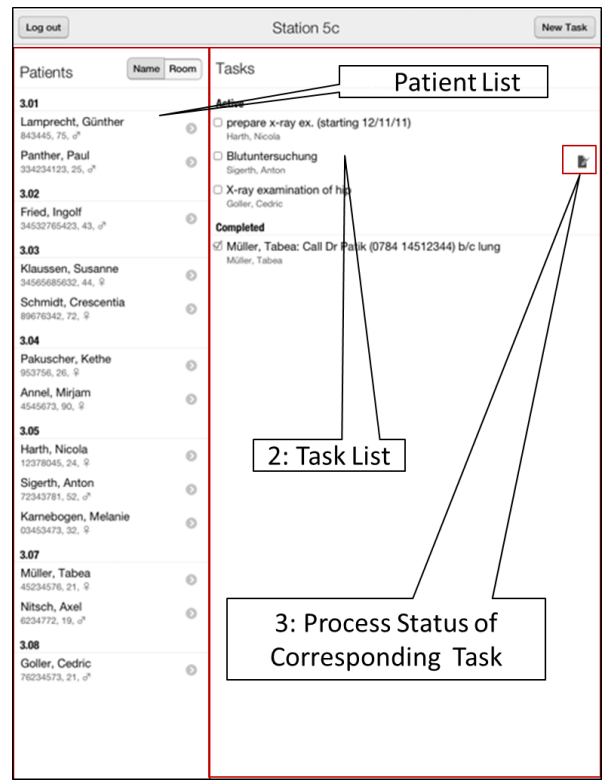

(a) Patient overview list

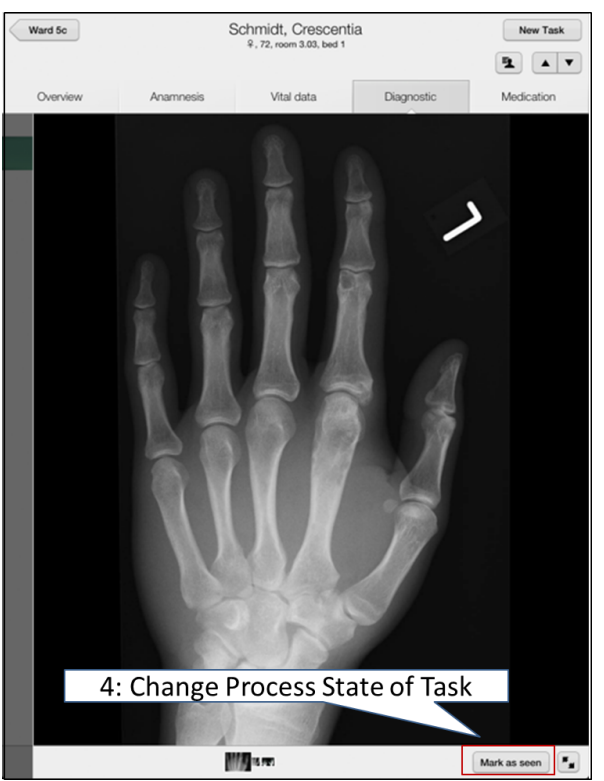

(b) Evaluation of X-ray image

Fig. 27. Patient overview list and X-ray diagnostic screen

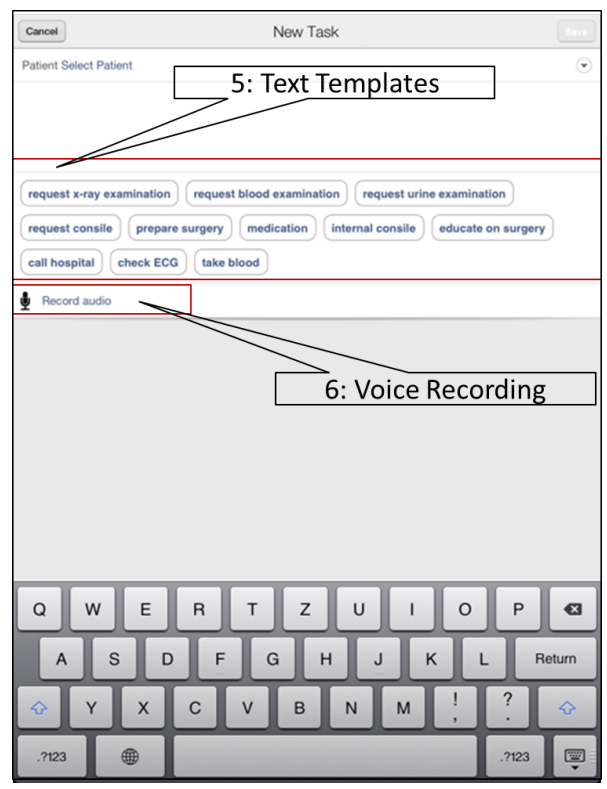

(a) Create task view

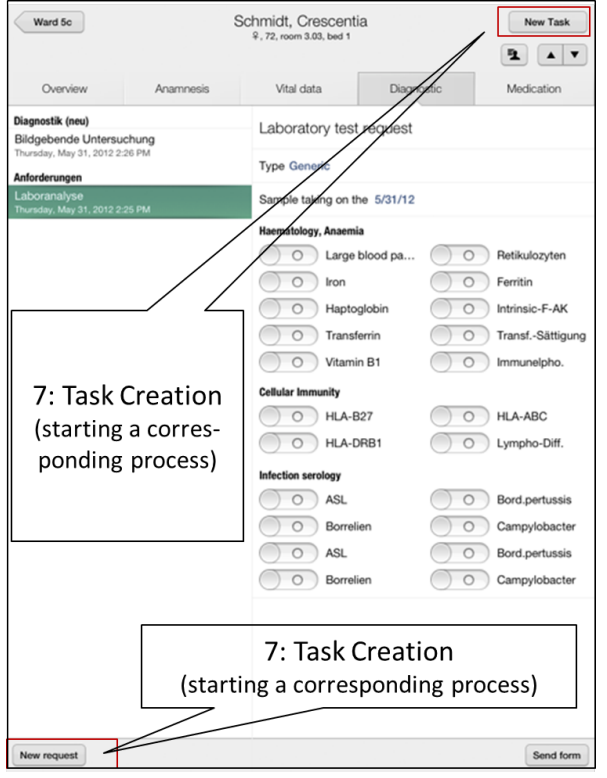

(b) Request for a laboratory

Fig. 28. Task creation and laboratory diagnostic screen 


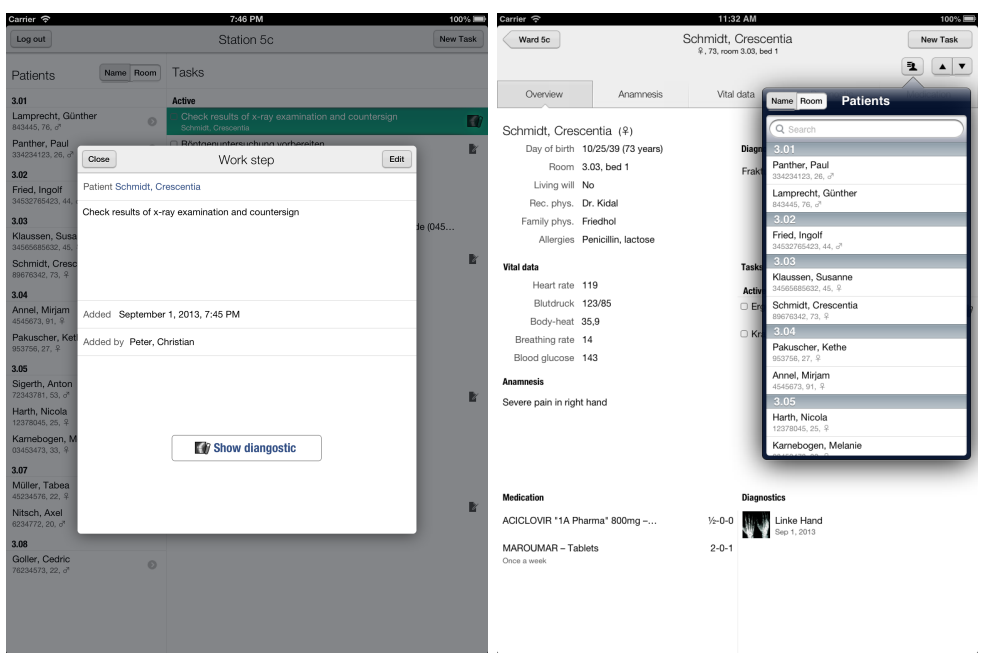

(a) Confirm blood examination re- (b) Smooth switch to another pasults tient

Fig. 29. Confirm blood examination results and smooth switch to another patient

\section{MEDo Evaluation}

In this section, the results of using MEDo are compared with the ones from Section 3 , in which we evaluated task management performed with pen and paper. To evaluate the usage of MEDo, the procedure shown in Fig. 30 was applied. Overall, 16 physicians ( 8 female, 8 male) and 9 nurses participated in the evaluation. Thereby, half of the participants had already worked with MEDo, while the other half did not. Based on the experiences reported in comparable work [13] as well as the knowledge-intensive character of ward rounds, we decided to conduct the evaluation procedure in a qualitative manner. Consequently, the test, which was not an experiment but rather a simulation, was performed in three phases: first interview phase, ensuing testing phase, and a second interview phase. The first interview round was based on general questions, while the last one comprised specific questions regarding the use of MEDo. The testing phase was accomplished in the following way: First, we explained four rules to the participants.

1. Participants may finish or interrupt the test whenever they want.

2. Participants shall think aloud.

3. If a participant is not able to finish a task, she may skip it.

4. The observer does not assist or help the participants.

Second, we presented a ward round scenario to the participants. Then, a participant was asked to accomplish nine tasks regarding the described scenario. Six tasks are related to the situation during a ward round, while three refer to the situation after a ward round. 


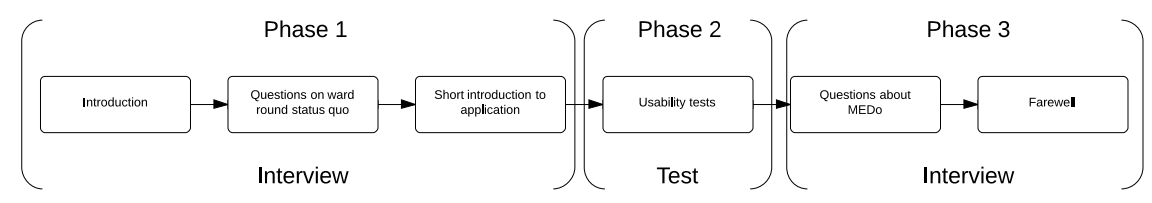

Fig. 30. Evaluation procedure

Due to limited space, we only present selected results of the evaluation (cf. Figs. 31-33). Fig. 31 shows how the participants perceived the overall information architecture as well as screen navigation provided by MEDo (on a scale with 6 values within the interval from 1 (very good) to 6 (inadequate)).

\begin{tabular}{lcc}
\hline Question & Mean Value & Standard Deviation \\
\hline Screen Navigation & 2.00 & 0.47 \\
Overall Impression & 1.90 & 0.50 \\
\hline \multicolumn{1}{c}{ | Scale range has 6 values within the interval : very good - inadequate | } \\
\hline
\end{tabular}

Fig. 31. Information architecture evaluation

In Section 3 (cf. Fig. 3), we presented results to questions how clinicians perceive overall task and ward round management without using any digital support. In turn, Fig. 32, shows results when using MEDo for task and ward round management.

\begin{tabular}{lcc}
\hline Question & Mean Value & Standard Deviation \\
\hline Task Definition & 1.90 & 0.50 \\
Ward Round Management & 1.80 & 0.53 \\
\hline \multicolumn{2}{c}{ | Scale range has 6 values within the interval : very good- inadequate | } \\
\hline
\end{tabular}

Fig. 32. Task definition and overall ward round management without MEDo support

\begin{tabular}{ccc}
\hline Question & Mean Value & Standard Deviation \\
\hline Patient Communication & 3.67 & 1.66 \\
\hline | Scale range has $\mathbf{6}$ values within the interval : very good - inadequate | \\
\hline
\end{tabular}

Fig. 33. Patient communication evaluation when using MEDo

Finally, Fig. 33 shows how clinicians perceived patient communication using MEDo. In summary, physicians classified the task creation with MEDo on the same production level as the one based on pen and paper. Furthermore, they 
appreciated the use of MEDo as process-aware assistance during ward rounds. Finally, they considered the close integration of (patient) data and process as one of the major benefits of using MEDo.

However, when interviewing with physicians, we also learned that patient communication was affected when using MEDo; i.e., intensively focusing on the mobile application might distract users from inpatients (cf. Fig. 33). Further research is needed to deal with this important issue. We further learned that the status of a process should be presented more intuitively to clinicians. Many staff members proposed a status notification similar to traffic lights, i.e., using three different colours for representing status information. Furthermore, physicians missed subcategories regarding the pre-specified text templates. Another demand was to integrate additional patient information in MEDo, e.g, reports from practitioners or surgery appointments. Finally, MEDo is supposed to be smoothly integrated into existing hospital information systems. Overall, physicians were satisfied with using MEDo (see and compare results from Figs. 3 and 32). After completing this test period, physicians pointed three additional issues not been considered so far.

- The buttons for creating tasks shall be individually placeable on MEDo screens. For creating a task, each physician has specific preferences depending on her context.

- Tasks should be better integrated with vital data signs and medication schemas. For example, if the medication of a patient expires, a reminder task shall be automatically added to the physician's worksheet in order to indicate that another medication might have to be created.

- Documentation becomes more and more complex in hospitals. Thereby, many activities are necessary which are not related to patient treatment. For example, legal requirements require to maintain statistical records. Physicians therefore asked for features enabling them to finish such activities.

Regarding the first issue, the described information architecture must be extended accordingly. The second issue can be solved through the integration of advanced process support features. Finally, the third issue raised needs to be investigated in detail in future research.

Limitations. Our evaluation on MEDo has the following limitations: First, the corresponding questionnaire was designed without the help of experts on survey design and therefore further evaluation is required to confirm the satisfactory results. In particular, the likert-scale was not symmetric and further efforts are necessary for the next evaluation cycle. Second, the number of subjects (physicians and nurses) in our exploratory study is relatively low (25 subjects), hampering result generalization. Nevertheless, it is noteworthy that the sample size is not unusual for this kind of empirical investigation due to the substantial effort to be spent per subject [14]. In particular, while evaluating MEDo with professionals, it frequently happened that they were interrupted or distracted by unforeseen situations around their patients, which made our investigation 
time-consuming, complex and challenging. Third, all participating subjects have been either ward physicians or nurses. In addition, physicians not directly participating in the ward rounds (e.g., physicians from the X-Ray unit), physicial therapists, and other professionals (e.g., from the laboratory) have not been involved so far, limiting result generalization. However, subjects indicated profound background knowledge regarding the issues of other professionals. Hence, we argue that they can be interpreted as proxies.

\section{Related Work}

In [15-17], approaches adopting mobile information technology to ward rounds are described. However, none of them focuses on mobile task assistance combined with a process support component, as done in the context of the MEDo approach.

The general importance of task support, in particular for scenarios characterized by concurrent tasks, is emphasized in [18]. Moreover, [18] considers scenarios for task support as well. Compared to MEDo, however, it does not consider process support as enabler for sophisticated task assistance. Besides, the information architecture used in [18] is not specifically tailored towards medical demands.

Other related work deals with the support of clinicians at the point of care [19, $20]$. However, an integrated view on patient and task status information, as provided by MEDo, is not available.

Another research field related to MEDo concerns the replacement of the paperbased patient record by an electronic surrogate [21,22]. Again, existing work does not focus on how the physicians organize their daily work. Similar concerns hold for approaches supporting ward rounds based on process management technology [5, 23-27] or transferring information technology to ward rounds [28, 13]. In addition, industrial solutions need to be considered, like the one running in the orthopaedic ward round (cf. Fig. 4) [29]. Either they focus on task management or mobile access to the hospital information system, but none of them integrates task management into daily work like MEDo does.

MEDo can be related to research targeting at the support of knowledge-intensive processes. Existing approaches like Declare [30], [31], ADEPT2, ProMInanD [32] and AristaFlow, for example, allow for an ad hoc composition of a process. Typically, these approaches rely on proper specifications of tasks and their management as well as their interdependencies. In contrast, MEDo is a lightweight collaborative task management tool, which allows physicians to focus on what tasks are supposed to be done instead of how. Hence, complex interdependencies between tasks are excluded.

In the context of knowledge-intensive processes, emerging approaches belong to the initiative of Adaptive Case Management and hence allow for a case and data-centric support, respectively, of knowledge workers [2,33]. These approaches differ from those dealing with traditional predefined business processes. Hence, MEDo can be regarded as contribution to this initiative as well.

Much research effort has been spent on examining how communication can be 
improved among (healthcare) professionals during ward rounds $[34,35]$. Finally, many studies can be found which underpin the goals of MEDo [36, 23, 37], but none of the approaches provided focuses on proper mobile task assistance in combination with smart process support.

\section{Summary and Outlook}

Existing information technology does not consider requirements of hospital ward rounds properly. With MEDo, we suggest mobile task management as a first step towards flexible user support during a ward round in particular and improved IT support of knowledge-intensive processes in general. Combining task management with process support has proven to be beneficial for healthcare professionals in this context. However, to use processes effectively, they must be well elaborated. We presented an in-depth analyses of four wards rounds and discussed them regarding their suitability for process and mobile task support. The insights we gained in this context have been used to tailor MEDo to the practical demands of clinicians. In particular, we illustrated aspects we consider as crucial regarding the replacement of paper-based worksheets. Finally, we have shown that MEDo eases overall ward round management.

In future research, we will extend MEDo by adding features like the ones discussed in Section 8. Furthermore, we plan to integrate two additional features. First, we want to integrate temporal aspects with process support of MEDo. To define, for example, when a process related to the planning of a surgery must be finished, is crucial in the context of ward rounds. Second, MEDo does not provide a feature to properly show all running processes at a glance. We have learned that users would consider this feature to be quite useful in certain cases. Furthermore, we plan evaluating MEDo under rigorous utilization. Thereby, we focus on unfavorable aspects (e.g., limited battery) imposed by mobile technologies in general and the used iPad for MEDo in particular. These insights shall be utilized to further improve MEDo.

Finally, the usage of best practice checklists represents an emerging and important aspect of everyday life in hospitals $[38,39]$. Following this, we plan to integrate corresponding results of dealing with paper-based checklists into MEDo. However, as discussed, using mobile technology during ward rounds might distract physicians and nurses (see [40] for similar concerns), an issue to be investigated in future research.

\section{References}

1. Davenport, T.H.: Thinking for a living: how to get better performance and results from knowledge workers. Harvard Business School Press (2005)

2. Swenson, K.D., ed.: Mastering the Unpredictable. Meghan-Kiffer-Press (2010)

3. Davenport, T.H.: Working knowledge: How organizations manage what they know (excerpt) (23.03.2011) 
4. Mundbrod, N., Kolb, J., Reichert, M.: Towards a system support of collaborative knowledge work. In: 1st Int'l Workshop on Adaptive Case Management (ACM'12), Proc. BPM'12 Workshops. Number 132 in LNBIP, Springer (2012) 31-42

5. Dadam, P., Reichert, M., Kuhn, K.: Clinical workflows - the killer application for process-oriented information systems? In: Proc. 4th Int'l Conference on Business Information Systems (BIS'00), Springer (2000) 36-59

6. Lenz, R., Reichert, M.: IT support for healthcare processes - premises, challenges, perspectives. Data and Knowledge Engineering 61 (2007) 39-58

7. Kennedy, M.M., Baker, D.J., Gurses, A.P., Pronovost, P.J.: Creating the ideal ward round. Organisation and management of intensive care. Medizinisch Wissenschaftliche Verlagsgesellschaft, Berlin (2010) 259-267

8. Pryss, R., Langer, D., Reichert, M., Hallerbach, A.: Mobile task management for medical ward rounds - the MEDo approach. In: 1st Int'l Workshop on Adaptive Case Management (ACM'12), Proc. BPM'12 Workshops. Number 132 in LNBIP, Springer (2012) 43-54

9. Eichwald, A.: Einsatz von prozess-management-technologie in der klinischen visite mithilfe der aristaflow bpm suite, Bachelor thesis, University of Ulm (2012)

10. Schobel, J., Schickler, M., Pryss, R., Nienhaus, H., Reichert, M.: Using vital sensors in mobile healthcare business applications: challenges, examples, lessons learned, 9th Int'l Conference on Web Information Systems and Technologies - WEBIST 2013 (2013) 509-518

11. Reichert, M., Weber, B.: Enabling Flexibility in Process-Aware Information Systems: Challenges, Methods, Technologies. Springer, Berlin-Heidelberg (2012)

12. Nielsen, J.: Usability engineering. Access Online via Elsevier (1994)

13. Ammenwerth, E., Buchauer, A., Bludau, B., Haux, R.: Mobile information and communication tools in the hospital. Medical Informatics 57 (2000) 21-40

14. Costain, G.: Cognitive Support during Object-Oriented Software Development: The Case of UML Diagrams. PhD thesis, ResearchSpace, Auckland (2008)

15. Carlsson, V., Klug, T., Ziegert, T., Zinnen, A.: Wearable Computers in Clinical Ward Rounds, Berlin/Offenbach, Germany. (2006)

16. Lamber, P., Ludwig, B., Ricci, F., Zini, F., Mitterer, M.: Message-based patient guidance in day-hospital. In: Proc. IEEE 12th Int'l Conference on. MDM '11, IEEE Computer Society (2011) 162-167

17. Kofod-Petersen, A.: Challenges in case-based reasoning for context awareness in ambient intelligent systems. In: 8th European Conference on CaseBased Reasoning, Ölüdeniz. (2006)

18. Camacho, J., Favela, J., Gonzalez, V.: Supporting the management of multiple activities in mobile collaborative working environments. In: Groupware: Design, Implementation, and Use. Volume 4154 of Lecture Notes in Computer Science. Springer Berlin Heidelberg (2006)

19. Dawson, L., Fisher, J., Heslop, L.: Investigating the potential improvement of patient anagement systems in hospital ward settings using mobile, wireless technologies. Mobile Government Consortium International LLC (2005)

20. Sawa, T., Okahara, M., Santo, M., Schmidt, U., Nakata, Y., Morita, S., OhnoMachado, L.: Preoperative information management system using wireless PDAs. Proc. AMIA Annual Symposium Proc. (2003)

21. Fitzpatrick, G.: Understanding the paper health record in practice: Implications for EHRs (2000)

22. Knaur, P., Pilz, J., Thalheimerc, M.: Can temporary paper-based patient records sensibly complete an electronic patient record? In: Ubiquity: Technologies for 
Better Health in Aging Societies, Proceedings of Mie2006. Volume 124., IOS Press (2006) 207

23. Heslop, L., Raikundalia, G.K.: Enhancing clinical nurse workflow through redesign of networked wireless laptop computers. Electronic Health Informatics 6 (2011) e25

24. Fitterer, R., de Witte, B.: Enabling pervasive healthcare by means of event-driven service-oriented architectures. the case of bed management in mid-sized to largesized hospitals. In: Pervasive Computing Technologies for Healthcare, 2009. PervasiveHealth 2009. 3rd Int'l Conference on. (2009) 1-4

25. Ali Fareedi, A., Tarasov, V.: Modelling of the ward round process in a healthcare unit. Volume 92 of Lecture Notes in Business Information Processing. Springer Berlin Heidelberg (2011) 223-237

26. Reichert, M.: What BPM technology can do for healthcare process support. In: Proc. AIME'11. Number 6747 in LNAI, Springer (2011) 2-13

27. Wang, L.: An agent-based simulation for workflow in emergency department. In: Proc. 2009 IEEE Systems and Information, IEEE (2009) 19-23

28. Bardram, J.E., Bossen, C.: A web of coordinative artifacts: collaborative work at a hospital ward. In: Proc. GROUP '05, ACM (2005) 168-176

29. SAP: Give caregivers secure mobile access to their patient data - with our mobile patient record apps. http://www54.sap.com/pc/tech/mobile/software/ industry-apps/patient-record-app/index.html (2013) [Online; accessed 06Mai-2013].

30. Schonenberg, H., Weber, B., Dongen, B., Aalst, W.: Supporting flexible processes through recommendations based on history. In Dumas, M., Reichert, M., Shan, M.C., eds.: Business Process Management. Volume 5240 of Lecture Notes in Computer Science. Springer Berlin Heidelberg (2008) 51-66

31. McCarthy, D.R., Sarin, S.K.: Workflow and transactions in InConcert. IEEE Data Eng. Bull. 16 (1993) 53-56

32. Karbe, B., Ramsperger, N., Weiss, P.: Support of cooperative work by electronic circulation folders. SIGOIS Bull. 11 (1990) 109-117

33. Chiao, C.M., Künzle, V., Reichert, M.: Object-aware process support in healthcare information systems: Requirements, conceptual framework and examples. International Journal on Advances in Life Sciences 5 (2013)

34. Alvarez, G., Coiera, E.W.: Interruptive communication patterns in the intensive care unit ward round. I. J. Medical Informatics 74 (2005) 791-796

35. Weber, H., Stöckli, M., Nübling, M., Langewitz, W.A.: Communication during ward rounds in internal medicine. an analysis of patient-nurse-physician interactions using RIAS. Journal Patient Education and Counseling 67 (2007) 343-348

36. Moran, E.B., Tentori, M., Gonzalez, V.M., Favela, J.: Mobility in hospital work: towards a pervasive computing hospital environment. Int'l Journal of Electronic Healthcare 3 (2007) 72-89

37. Ho, D., Xiao, Y., Vaidya, V., Hu, P.: Communication and sense-making in intensive care: an observation study of multi-disciplinary rounds to design computerized supporting tools. In: Proc. AMIA Annual Symposium. Volume 2007., American Medical Informatics Association (2007)

38. Haynes, A.B., Weiser, T.G., Berry, W.R., Lipsitz, S.R., Breizat, A.H.S., Dellinger, E.P., Herbosa, T., Joseph, S., Kibatala, P.L., Lapitan, M.C.M., Merry, A.F., Moorthy, K., Reznick, R.K., Taylor, B., Gawande, A.A.: A surgical safety checklist to reduce morbidity and mortality in a global population. New England Journal of Medicine 360 (2009) 491-499 
39. Weiser, T.G., Haynes, A.B., Dziekan, G., Berry, W.R., Lipsitz, S.R., Gawande, A.A.: Effect of a 19-item surgical safety checklist during urgent operations in a global patient population. Journal Annals of Surgery 251 (2010) 976-980

40. Alsos, O.A., Dabelow, B., Faxvaag, A.: Doctors' concerns of PDAs in the ward round situation. lessons from a formative simulation study. Methods of Information in Medicine 50 (2011) 190-200 